Portland State University

PDXScholar

7-31-2018

\title{
Learner power! The Benefits of Metacognition and Transparency on Education Justice, Insights from Neuroscience of Learning
}

Camille O. Nava

Portland State University

Follow this and additional works at: https://pdxscholar.library.pdx.edu/honorstheses

Let us know how access to this document benefits you.

Recommended Citation

Nava, Camille O., "Learner power! The Benefits of Metacognition and Transparency on Education Justice, Insights from Neuroscience of Learning" (2018). University Honors Theses. Paper 637.

https://doi.org/10.15760/honors.652

This Thesis is brought to you for free and open access. It has been accepted for inclusion in University Honors Theses by an authorized administrator of PDXScholar. Please contact us if we can make this document more accessible: pdxscholar@pdx.edu. 


\section{Learner power!}

The benefits of metacognition and transparency on education justice: insights from neuroscience of learning.

by

\section{Camille O. Nava}

An undergraduate honors thesis submitted in partial fulfillment of the

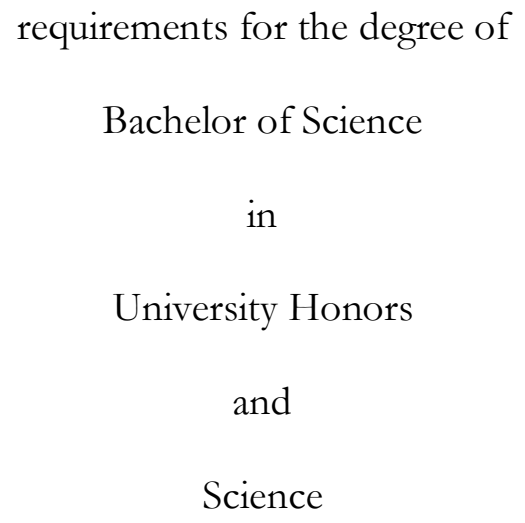

Portland State University 


\begin{abstract}
:
Emerging understandings from neuroscience and cognitive research on human learning indicate that nearly all people can learn, and that we can do so throughout our lifetimes. Simultaneously, public health research from the late 1990s identified Adverse Childhood Experiences (ACEs). This research connected ACEs to incidence of factors impacting children's development (including cognitive and educational) and possible long-term impairments to life outcomes. Incidence of impact factors is correlated with effects of poverty and socioeconomic status, especially as the experiences of poverty can create neural stress impacts similar as those resulting from ACEs. Specific insights from ACEs-related research identifies developmental impacts to attention, behavior, comprehension of mathematics and reading. However, our brains possess neuroplasticity, meaning we can create new neural pathways from input and stimulus. Understanding trauma's impacts in light of the brain's capacity to create new patterns, and helps educators develop possible educational approaches to a range of educational concerns. These concerns include classroom behavior issues, learning progress, and engagement with healthy social spheres. Many best practices exist for trauma-informed and poverty-impacted learning settings which focus on supporting protective factors and on supporting the mitigation of risk factors in a learner's life, and often include fostering development of a learner's executive functions. This paper delves into muchstudied areas where deleterious conditions persist, and emphasizes the approaches of metacognition (thinking about one's own thinking, learning about one's own learning) and transparency, while considering the educational future taking shape now with large, swift global technological changes in learning. This paper is a qualitative literature review considering education and learning for trauma and poverty affected learners (K-12, predominantly). This paper argues that education justice for all learners requires more cohesive application of techniques to teach all learners, specifically an increase in the use and application of metacognitive tools and transparent practices. Also considered are aspects of emerging education trends like globally connected learning, universal learning goals, blended learning and the flipped classroom, alongside questions of education justice and Khan Academy. Contained is an additional review of Khan Academy as an example of such a learning model which may represent part of the future of education.
\end{abstract}


Table of Contents

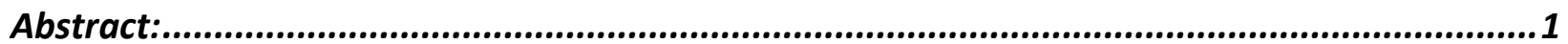

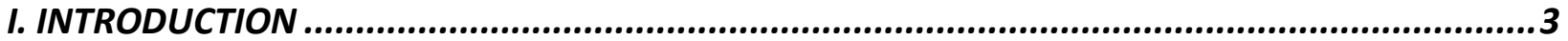

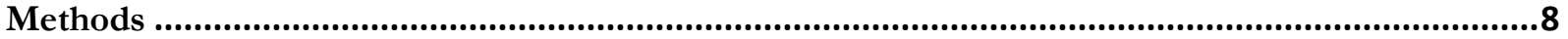

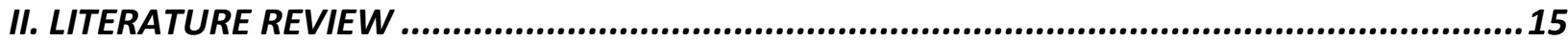

Prevalence and Universality of poverty and Adverse Childhood Experiences (ACEs) ...................16 Economic disparities and digital technologies in education ................................................................... 17

Biology and input: how learning works, an overview of current working theories ........................18 School readiness, attachment theory, and executive functioning ...................................................... 19 What is metacognition? Helping learners recognize patterns of thinking. .............................................. 20 Best practices: supporting protective factors and supporting mitigation of risk exposure......................... 23 A school or district's strong academic focus and transparent practices empower the learner ................... 24 Efficacy: our own beliefs and expectations about what we can do can impact cognition and academic

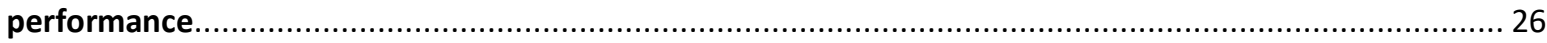

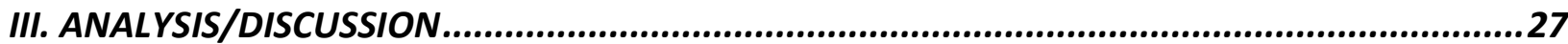

\#1: Metacognition: a user's guide to our brains, development and cognition: Metacognitive

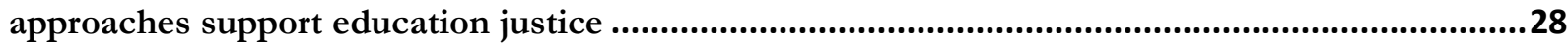

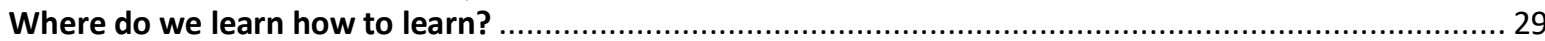

\#2: Transparency, a lens for supporting education justice ..............................................................30

\#3: Education for all learners: examining content and ....................................................................31

point of view for all instructional material ..........................................................................................31

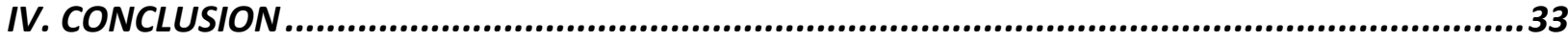

Addenda I: Content analysis: digital blended learning, global education, Salman Khan: education justice, metacognition and transparency ....................................................40

Khan Academy and the trauma and poverty-impacted learner ............................................................ 40

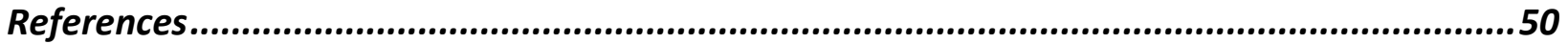

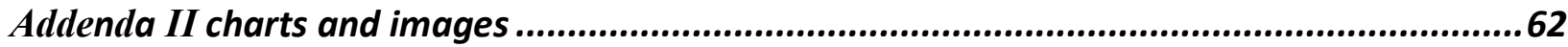

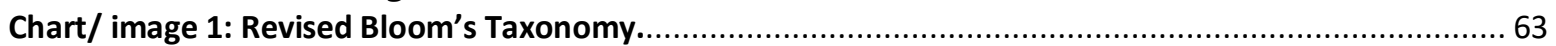

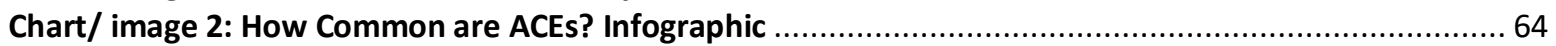

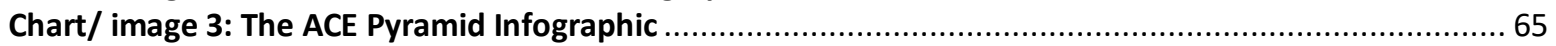

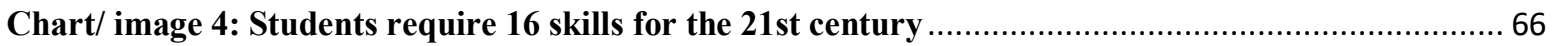

Chart/ image 5: A variety of general and targeted learning strategies foster social and emotional skills.... 67

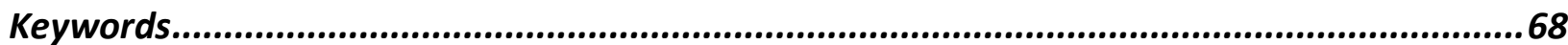




\section{INTRODUCTION}

We are now beginning to understand from a brain-science perspective how our diet, stimuli and circumstances from the world around us — social, emotional, physical and chemical — literally shape our developing brains and control the size and functionality of certain brain regions and the synapses or connections made therein. We also are beginning to understand the brain's ability to repair or restore function and form new neural pathways, the keys to neuroplasticity. This is exciting news and holds promise for children and classrooms everywhere. This paper focuses on K-12 learning in the United States and considers two public health concerns that can greatly affect a student's ability to learn, trauma and poverty. Statistics and data for trauma and poverty are from governmental sources, Centers for Disease Control and Prevention (CDC), U.S. Census, U.S. Department of Education, and informed by Organisation for Economic Cooperation and Development (OECD), which will be mentioned further on in the paper. Over fifty percent of today's K-12 classrooms in the United States public school system have students from low-income economic backgrounds. A recognized proxy measure for poverty in education is the use of USDA free and reduced meal reference. (Poverty measures vary greatly, across governmental levels. In Education, the term low socioeconomic status, SES, often refers to impacts from poverty. One measure states use to allocate additional educational funding is the amount or percentage of USDA free and reduced meals, (Implementation of the SB 287, 2011.).)

No less than one in five youth (children under 18) are trauma-affected, according to the CDC. Trauma's impact on children is recognized as a global public health concern, as is poverty. Poverty can create chronic stress in a child's life and can be coupled with less access to resources and fewer sources of support, and chronic health issues (Teaching Children from Poverty and Trauma, 2016). Poverty and exposure to childhood trauma often overlap, but not necessarily so; trauma's impact on children is found across the population (Blodgett, 2016). These figures are 
intended not to be combined, but to help create a context for when one may glance around a room of people and imagine the likelihood of encountering a person who has experienced trauma or poverty. Both trauma and poverty can impact learning, as shown in cognitive neuroscience, and as demonstrated by measurable life outcomes which will be discussed below. These impacts may not be permanent, depending on the learner's exposure to positive conditions which support resilience (adapted from Blodgett 2018). A person's impact by trauma or poverty is recognized to be highly individual. Effects of trauma and poverty may express differently based on a range of community and individual factors, but for this paper, the terms will be used to describe both their potential to impact cognition and learning, and to address the societal deleterious life outcomes that can stem from each. Neuroscience and education recognize the need to consider the individual person when considering traumatic impacts. "When we think that kids just need willpower to overcome adversity, we miss opportunities to provide the relationships and build the skills that can actually strengthen resilience" says Jack Shonkoff chair of the council and director of the Harvard Center for the Developing Child (Harvard Graduate School of Education, 2015).

Trauma and poverty may interrupt attainment of knowledge, putting the learner behind the class' pace (which can also be traumatic for the learner and peers). Impacts may be expressed as certain disruptive classroom or school behaviors (which were previously called discipline concerns). Some learners disengage from learning and the academic setting, becoming withdrawn or engaging with social spheres that put them in more jeopardy (more exposure to risk). Effective standards for trauma-informed classrooms (schools and communities) emerged as a response. These include a distinction that teachers are not psychologists or therapists, but that they can use classroom techniques that may help the trauma-impacted learner and foster a safer learning setting in the classroom for all students. These also include school and district wide recommendations that the school conduct screenings for trauma and many of today's program recommendations include that 
all staff and faculty receive trainings on how to identify trauma and inform the trauma care personnel when they do. Holistic, community-wide sensitivity and trauma awareness approaches are quite likely the best next step, but this paper focuses on shifts in viewpoint at and toward the learner-level. Also, much work nationwide has focuses on early childhood support, which is essential. Best practices also emerged to support learners with Social and Emotional Learning (SEL), build resilience, foster safe and supportive learning, learn from high-performing high-poverty schools, and develop metacognitive skills (thinking about one's own thinking and learning about one's own learning). The practices and standards discussed here are evidence-based or evidenceinformed. These standards and practices are discussed here in simplified versions, and in general, the best use of any set of standards is when they are appropriately applied for age and developmental progress, along with regional and cultural factors. It is widely understood that trauma-sensitive and poverty-sensitive approaches to education benefit all learners and their communities in general. This is not one-size-fits-all, but properly handled, these approaches are considered good for fostering the social intelligence of everyone involved.

Before I began work on this paper, I wrote a model for re-engaging learners who had experienced trauma. I was working on the details for $\mathrm{K}-3^{\text {rd }}$ grade, and $3^{\text {rd }}$ grade - high school. As I began the search for my thesis topic, I wondered how I might approach my thesis through documenting my model. Very early in the research, I realized I had stepped into the flow of education reformers. (In this context, reformers seek major structural overhauls of current systems and practices, often seeking to bypass what they feel are broken systems with a viewpoint that some problems are intractable). Once I began to consider trauma-impacted learners in the context of education reform, the shape of my inquiry shifted, as did my recognition of poverty and inequality's impacts on learners. With guidance from my thesis advisor, Dr. Joshua Eastin, my research question 
became: "What resources are available and effective to help K-12 students with trauma and poverty impacted backgrounds to engage or re-engage with learning? How might this be improved?”

Today's mission for the United States Department of Education reads “to promote student achievement and preparation for global competitiveness by fostering educational excellence and ensuring equal access" (U.S. Department of Education, 2018). This paper considers the trauma and poverty affected learner in the context of education for all learners, during a globally-connected time. As reflected in the above mission statement, we are preparing a workforce with new skills, driven by technology (our need to be adept at learning and using increasingly more sophisticated technology and the marketplace's need for humans to create and operate new technologies). Education seems to be headed in an increasingly digital and global direction, which will likely not surprise any reader. Some of what I found surprising during this research was how quickly some aspects of digital education had grown, especially for K- 12 foundational learning (foundational referring to education that addresses the learner's academic foundational needs, as opposed to an example like a game which may support a certain aspect of learning).

Online learning, video based online learning, and many other computer and internet-based learning are tools with global reach. Khan Academy provides educational content free to the user, globally. Khan Academy works to help ready the learner to become part of the new workforce and they also have a mission statement of commitment to learning for all: "Our mission is to provide a free, world-class education for anyone, anywhere" (Khan Academy, 2018). Their home page opens with: "You can learn anything. For free. For everyone. Forever." They produce content video lessons which can supplement K-12 learning to US Common Core (more on Khan Academy's learning offerings to follow). Khan Academy envisions their lessons not as replacements for classroom learning, but to provide an opportunity for learners to essentially review the lecture portion of class before class, or to review prior learning and help clear up any confusion or gaps in 
comprehension. The hybrid video and physical class approach is called "blended learning" (which Khan regards as part of their following of "flipped classroom" practices). There are education observers worldwide who are cautious about blended learning being largely untested (a critique that they are not evidence-based) and that it is too closely tied to global technology-culture and marketplace. ${ }^{4}$ Every Child Succeeds Act (ESSA) emphasizes the use of evidence-based practices in education and clarifies their definitions of evidence-based practice, assigning levels like strong or moderate (Non-regulatory guidance, 2016). Khan Academy is now a sizable global provider of free education for children, a provider whose education is technology platform-based, and has a claim that it is for all learners. This paper considers trauma and poverty-affected learners in the blended models of Khan Academy and Khan Lab School (their one pilot brick-and-mortar school), while examining their teaching of metacognitive skills and social emotional skill development. New Vision for Education (2016) reports a return of investment for social emotional learning as $\$ 11$ for every $\$ 1$ spent. $^{5}$

\footnotetext{
${ }^{4}$ Note: I have not observed that Khan Academy uses this term when describing their philosophy or product; further, I have observed that they are very select and consistent in their use of any education or theoretical jargon.

${ }^{5}$ I have noted economic return-on- investment measures in education used by stakeholders from a range of viewpoints, including social justice and education equity, policy advisement groups.
} 


\section{Methods}

I began this paper asking "what resources are available and effective to help K-12 students with trauma and poverty impacted backgrounds to engage or re-engage with learning?” I initially expected to look at community-based resources (not formal classroom), but I found that most of that literature focused on early childhood education and I generally encountered difficulties with finding relevant literature. In discussions with my advisor, he guided me to focus on what was driving me to ask these questions, which was an interest in analyzing and discussing helpful tools for these learners. He encouraged me to focus on "how might these resources be improved, focusing on a set of recommendations?” For this literature review, I sought an understanding of essential information from the fields that underlie trauma and poverty-informed best practices. These include fields and topics of education, metacognition, equity, policy, neuroscience, aspects of attachment theory, ACEs and poverty, with the focus of looking for relationship to trauma and poverty impacted learners.

I reviewed and analyzed peer-reviewed qualitative and quantitative research, books, policy and programs, professional and occupational resources, and news media. A list of keywords (which built and grew over time) is listed below the bibliography. This paper primarily used search engines Google Scholar, broader Google searches, ERIC and EBSCO databases supported by Ed.gov.

I also sought as much as possible to verify the researchers whose work I reference. I looked for and reviewed researchers' profiles, any academic, governmental or professional pages they may have. I followed select education journalists, think tanks, and bloggers in order to get more perspectives. Most of my online research was conducted through the PSU Library internet portal, mainly at home and on campus. My literature search expanded to include public records, nonprofit or governmental best-practice recommendations, public health documents and government websites, education journalism, conference proceedings, YouTube and other online video content. 
Current statistical population and demographic data was sourced from government and NGO websites.

I started this paper with an assumption that there are few available and effective resources for these learners. There is potential bias in my work, including in the selection of main points and factors I considered. Also, there is a real-time aspect to this paper, as some of the social phenomena on which I comment may be unfolding faster than data-driven findings can be produced. I sought to present a body of work with real-world applications, based on a synthesis of multi-disciplinary current findings.

My initial methodological approaches included the assumption that some or all of the factors I have selected are not of substantial impact to learners, or a null hypothesis. I also recognized that some factors conjoin (or amplify or negate) with other factors for impact, and other similar variations. Another rival hypothesis would have been that there were ample and sufficient educational resources for these learners. If I had found significant data trends which indicate that there is great equity for these learners, and that the quality-indicators (outcomes) of their lives indicate such, I would acknowledge the error of my assumptions. This paper would have benefitted from team research and quantitative analysis: this is a limitation of my paper.

This paper includes a content analysis of Khan Academy (the online learning platform). and Khan Lab School, for which the paper uses different methods because of availability of information. In this paper, Khan is a bell weather for fast, emerging technological changes to education, and the content analysis provides a place in the paper to look at application of pedagogical and social theories, in context. For Khan Academy, I reviewed: Salman Khan’s 2012 book, Education Reimagined; all links on Khan Academy's website and reviewed their YouTube page; I sourced interviews, keynote and panel talks featuring Khan; and I sourced videos and news articles with staff or board or advising members. I searched Khan's lessons on these topics: social justice, 
inequality, cognition/metacognition/learning how to learn, poverty, and trauma. I analyzed the six lesson videos Khan has for cognition topics (which are not led by Khan himself); an older lesson led by Khan, and a newer lesson led by Khan. In video analysis, I looked for how the videos created a connection to the learner (gestures, tone, personal comments, humor); explicitness of instruction (and what were they pruning out the lesson?); how (if) they referred to the source of the content that they're teaching (an education justice perspective); how the instructor presented the material (is knowledge presented without discussing the source? is knowledge presented in context of real-life application?); where the videos provide opportunity for active learning and for applying progressively more sophisticated thought; and metacognitive methods. (Active learning is an approach that aims to break up lecture-time, and to actively involve the learner in doing some action with the knowledge they are learning. It also aims to engage learners in cognitive tasks across the spectrum of Bloom's Taxonomy (see Chart/ image 1: Revised Bloom's Taxonomy), in order to enhance memory and stimulate activity in a variety of brain regions.) I selected two talks for close analysis, a panel talk and a keynote ${ }^{6}$. In the talks, I listened for any mention of trauma, poverty, metacognition, and social-emotional learning. I listened for how Khan presented how the nonprofit works with schools around the globe. I searched all available media for the most current data on their number of registered users, number of languages in which their content is now available and culturally-customized; any population characteristics data or analytics they may have made public, any research, reports or findings they may have made public, and for any peer-reviewed research on Khan Academy. There is fascinating research on the role of instructor's use of gesture in the classroom, note Hattie and Yates 2014. Gesture-use can help learners' imprint memory and impact

\footnotetext{
${ }^{6}$ Skoll World Forum, Disruption. (2013). Blended Learning: The Proof and the Promise, Salman Khan, Sandy Speicher, Stacey Brewer, and Debra Dunn. Retrieved from http://skoll.org/2013-skoll-world-forum-disruption/.

ACM Conference on Human Factors in Computing. (2016). Closing Keynote Salman Khan, Education Reimagined. SigChi. Retrieved from https://www.youtube.com/watch?v=dNwvhPsFrnU.
} 
learning, note Hattie and Yates 2014. They also highlight the importance of instructor's becoming aware of their facial gestures and type, and duration of smiles, which can have impact on children (Hattie and Yates 2014). Of course, not all learners respond in the same ways to gesture and facial expressions, and the trauma-informed classroom trains instructors on development-appropriate classroom suggestions. A video-format lesson which does not visually include the instructor may bypass some areas of unintended human communication, and it still can convey social connection, aspects of which will be considered in Addenda I on Khan Academy.

In my research, I have not located any place or comment made where Khan expressly mentions poverty or trauma's impact on learning, or that any of their practices are trauma or poverty informed. I had enough familiarity with Khan's education philosophy and Khan Academy lessons to decide to look for practices or comments which might shed more light on whether trauma and poverty informed education had been factored into their teaching. Khan Academy's website and YouTube site contain thousands of their video lessons and many brief informational videos but very little information on things like policies, practices, and teaching philosophy. What this paper sought to find is examples of where Khan Academy and Lab School may employ evidence-based techniques for trauma and poverty-sensitivity and to suggest ways that Khan Academy and Lab School may strengthen their curricula for all learners going forward.

For Khan Academy Lab School, there were documents available on their website addressing their teaching philosophy and approach. I selected these six documents for analyzing: Learning Design; Approach to Learning; Architecture of Learning; Academic and Character Outcomes; Art of Teaching; and Curriculum.

The content analysis was used to inform my comparison of programmatic approaches (namely trauma-informed education, poverty-informed best practices, resilience informed practices, and the practices demonstrated in Khan Academy and Khan Lab School) and to comment on their 
possible internal measures of effectiveness. It has become evident that answering the question of whether programs are "available and effective" is highly subjective unless I performed a quantitative survey, which is beyond the scope of this paper.

Since the paper's scope includes many topic areas, it was essential for the rigor of my qualitative review that I consult with topical experts in their fields. I had informal conversations with professors from academic disciplines of Political Science (including comparative public policy), English (including topics of research for writers), History (including topics of self-reflection of service learning and the role of power), Anthropology, Biology (including topics of scientific approaches to teaching and the teaching of the sciences), Neuroscience, Graduate School of Education. during which I asked the following five questions: 1) Am I missing anything? 2) Does anything about my approach or findings thus far sound incorrect? 3) Is there anything else I should be looking at? 4) Anyone else with whom I should be speaking? and 5) What else should I be considering? All conversations were in their PSU academic offices, in the academic quarters of Spring 2017, Winter 2018, Spring 2018 and Summer 2018. Search-term refinement and research support came from meetings with PSU research librarians with topical expertise in education, urban \& public affairs, social work \& social sciences.

Parents, educators and peers, and professional therapists, were also eager to share stories. Through these informal conversations, this paper began to be informed of the connections between learning disabilities, disabilities, bullying, gender and sexuality identity, identity-related bullying, and their traumatic impacts on learning and families. Many informal conversations also informed me of the immense strain and frustration that learning disabilities have on learners and families. Families shared that a learning disability diagnosis or misdiagnosis can traumatize students and keep learning at bay, by singling out the child, or by difficulty in obtaining services that are helpful for and matched to the student's needs. (Adams 2013 notes that a 2011 study by Dr. Nadine Burke Harris 
found that children with an ACE score of 4 or more were 32 times more likely to receive a label of behavior problems or learning disability.) Recent evidence questions the validity of learning style differences but my informal conversations with learners and families indicate that there is much more to the picture.

I volunteered for one academic quarter in a classroom in mid-sized metro high school located in the Pacific Northwest as an English language mentor in an immersion classroom (English Language Development). Pseudonyms are used and further description of classroom redacted for student privacy. Conversations with the class' teacher, Ms. Focused, brought to life academic, educational, policy and social issues of the paper's topic areas. Working in her classroom provided additional vital insights such as technology-use insights and aspiration insights from students' and educators' aspirations often in cases where there are challenges of attainment for the learner.

As a student, I note my own metacognitive processes throughout research and writing. Though observation, I have deepened my experience of my cognitive process of working with my initial ideas, through the stages of analysis, retrieval and connection, into what I will call understanding. In classic taxonomy lingo this would be knowledge, but in fact, I am still in the process of discovery and in the researcher's mindset. I have observed gaps in my factual knowledge, and in my understanding where I had made unexamined leaps in logic. The process of writing is metacognitive. And through it I not only review my factual/informational cognitive process, but I observe where I need to continue development of skill and knowledge, broadly and specifically, planning which comes from executive functioning and expresses applied academic self-efficacy. The development of my executive functioning and academic self-efficacy continues to be cultivated. Hattie and Yates 2014 refer to knowledge building in this way: "expertise develops as learners mindfully combine simple ideas into more complex schemata" (the term "schemata" refers to basic 
units of information used by the brain to build knowledge, p 147). I am increasingly grateful for exposure to the tools for developing executive functions.

Vital issues of race and education equity, gender, migration immigration and refugee (global and domestic) are not addressed in this paper. The absence of any essential information, context, or population, is solely my limitation. This paper will address learning style differences as a factor that families and learners and many educators still find valuable and vital, while recognizing that: 1) there is new evidence in the field that questions this and 2) Salman Khan himself finds validity in the newer evidence questioning learning styles differences. It is beyond the scope of this paper to address learning styles in more depth.

The literature review discusses childhood trauma and poverty's impact on learning, with insights from a public-health perspective. Also discussed in the literature review are key insights from neuroscience and psychology on social-emotional conditions expressed in classroom and during cognitive tasks. Educational programmatic approaches of trauma and poverty-informed practices are discussed. Insights from metacognitive tool-use for learning and self-regulation are woven throughout these topics. 


\section{LITERATURE REVIEW \\ Understanding effects of trauma on life outcomes}

In the late 1990s, landmark research from CDC and Kaiser Permanente captured public health attention here in the United States and followed quickly with international attention. This research identified what is now known as Adverse Childhood Experiences (ACEs) and identified from a health perspective that traumatic or adverse childhood experiences impaired life outcomes (e.g., diminished life span, higher likelihood of incarceration, higher likelihood of chronic disease, and reduced educational and income outcomes). The initial study was 1995-1997 and looked at a population of 17,000 people. There are numerous related studies, including longitudinal, and ongoing today. Traumatic childhood experiences identified in the initial study included exposure to violence, abuse, and divorce of parents. Since that time, recommendations for broadening ACEs to include poverty, war, bullying, racial, gender and identity discrimination, migration and refugee movement and displacement, emerged from global public health conversations. The ACE model creates a number, of each occurrence of an ACE, resulting in a learner's ACE score. From the initial two waves of the studies, the CDC reports that approximately $12.5 \%$ had four or more ACEs, nearly $10 \%$ had three, $16 \%$ two, $26 \%$ one, and $36 \%$ had zero (CDC 2016). These scores may not reflect poverty unaggregated from other traumas. (See Chart/ image 2: How Common are ACEs? Infographic and Chart/ image 3: The ACE Pyramid Infographic). As mentioned, poverty is not categorized as an ACE. It is important to note that exposure to ACEs may not result in trauma due to support or buffering of elementary-aged child's life (Blodgett \& Lanigan, 2018). In their survey of research, (Blodgett \& Lanigan, 2018), reference that higher ACEs are associated with specific academic outcomes. Notable examples include impacts on attention, reading comprehension, mathematics, classroom behavior, and attendance. This work suggests some of the support that school and education can provide to trauma-affected learners that is well within the scope of a school's capability and focus. 
Prevalence and Universality of poverty and Adverse Childhood Experiences (ACEs)

Over $51 \%$ of current public-school students in the United States are low-income (Southern Poverty Law Center, 2013). At minimum, half ${ }^{7}$ of all K-12 students in the United States are traumaimpacted (the CDC reports: "Adverse Childhood Experiences (ACEs) are common. Almost twothirds of study participants reported at least one ACE, and more than one in five reported three or more ACEs. Dr. Chris Blodgett (2016) reported that ACEs are the single most important measure in determining a child's success in school. He describes their impact as being found in every continent, and prevalent in societies worldwide (Blodgett, 2012). Poverty is considered to be a leading determinant of impact on learning and education; and educational attainment is considered globally as a social determinant of health, wealth and life outcomes (Centers for Disease Control and Prevention, 2018 and Hochschild, 2003). These impacts are cyclic and interconnected. Higher incidence of ACEs is found with lower income and lower educational attainment, and that with lower incidence of ACEs are found with higher income and higher education-attainment, cite Metzler, Merrick, Klevens, Ports and Ford (2016). Nearly all governments today declare commitment to equity in education as societies grapple over the complexities of education equity ${ }^{8}$ (for this paper, education equity is fairness of educational opportunity and inclusion of all learners (Field, Kuczera \& Pont, 2007).

\footnotetext{
${ }^{7}$ Education Law Center cites "between half and two-thirds of all school-age children experience trauma" Retrieved from https://www.elc-pa.org/wp-content/uploads/2015/06/Trauma-Informed-in-Schools-Classrooms-FINALDecember2014-2.pdf

${ }^{8}$ For this paper, education equity is fairness of educational opportunity and inclusion of all learners (Field, Kuczera, \& Pont, 2007).
} 


\section{Economic disparities and digital technologies in education}

Economic disparities in education manifest through the use of digital technologies in the classroom, referred to as the "digital divide" which can become part of the "achievement gap." Purcel, Heaps, Buchanan and Friedrich (2013) point to economic disparities as a factor on how students use technology. If the digital divide at its simplest is the economic diving line between who has access to what quality of computers and internet, further examination of a possible divide phenomena reveals that wealth impacts how users use the technology and internet available to them. In their 2013 work, Purcell, Heaps, Buchanan, and Friedrich look across factors related to digital technologies and education to gain insights into the differences between digital technology use by income (teachers of and students by students' household). The report reflects that students from higher incomes report more home access to digital tools and connection. Notably, teachers of the students with higher incomes are reported to have more digital training that teachers of lower economic students. They report that 56\% of teachers (public school teachers) surveyed in 2012 responded that the use of digital technologies led to greater overall academic disparities in rates of students' success, widening the gap commonly called the "achievement gap," while 44\% of teachers responding that digital technology did not widen the achievement gap between students. Also notable, the highest percentage of teachers responding that digital technology use widened the achievement gap were teachers of both the lowest and highest income students. Interestingly, they also report teachers with specialized training (Advanced Placement and National Writing Project teachers) reported more personal use of technology. This suggests links between affluence factors and increased technology use. 


\section{Biology and input: how learning works, an overview of current working theories}

Findings from psychology and executive functions of our brains illustrate relationship between environment \& cognition, also between learned behaviors \& academic success. Human brains require input to develop and grow; this understanding highlights the role of social interpersonal communication and stimulus-providing in helping a child develop. Weiss and Wagner (1998) assert that neuroscience work confirms that most humans begin with the same brain material to achieve genius. When the brain grows, especially during pre-adulthood and most readily in our earliest years, it dramatically increases in the number of neurons (nerve cell) and in synaptic connections, which are the brain's pathways for information, also called neural pathways. This brain growth is stimulated and enhanced by input and use, and in fact the brain prunes or repurposes unused pathways. Human genius potential, they conclude therefore, is differentiated from other human development. That isn't, of course, the final uncontested word on how human learning works. The human brain also needs nutrition, adequate blood flow and sleep, and research is beginning to provide more insights into the relationship between chemical and hormonal production stimulated from social and environment conditions, as well as into how gene expressions can be impacted (Kaufer, 2011). The brain increases in synaptic connections when the human brain receives input from a child's environment, especially so when it is during the optimal developmental time. From a neuroscience and human development perspective then, it follows that responsibility for opening human potential becomes shared by all people encountered by children, especially in learning settings. As Roskams (2014) notes, "Behavioral / intellectual environment can enhance neuroplasticity, neurogenesis, and change epigenetic signatures”.

I believe in the potent message that biological bases form a greater understanding of our species' learning as a mutual process: in my view, this is a tool for equity. I recognize science and biology are and have also been complicit in creating further conditions of oppression and 
marginalization. Rich 2017 in his review of PBSs 2016 film School of the Future cautions that both science and technology have been complicit in subverting education claims for gain and prestige. Education researcher Paul Gorski 2016 urges that educators shift their thinking when considering poverty-impacted students away from deficit thinking and toward education justice. The viewpoint of my paper is that the roots of inequality stem from the impacts from inequality, marginalization and oppression. Dr. Christopher Blodgett cites both individual-level and school-level poverty as a factor impacting school readiness; he also correlates community-wide ACEs with reduced school readiness outcomes ${ }^{9}$.

\section{School readiness, attachment theory, and executive functioning}

The tools for a learner to be school-ready are largely the domain of the brain's executive functions, healthy development of which relies on healthy human attachment. In a review of studies from neuroscience, Cassidy, Jones, and Shaver (2013) correlate school readiness with a child's foundation of a healthy human attachment with a caregiver (referred to as attachment, or a safe bond with a nurturing caregiver), and links the importance of attachment and self-regulation on school readiness (self-regulation refers to the ability to plan for one's future and address complex, multiple tasks, also called executive functioning). Harvard's National Center on the Developing Child highlights how critical executive functioning skills (working memory, inhibitory control, cognitive or mental flexibility) are in classroom and learning contexts. They assert: "Executive function skills are both building blocks for the early development of both cognitive and social capabilities” (Building the Brain’s Air Traffic Control, 2011, p. 3). In clinical settings, an Executive Function Composite tool assesses working memory, inhibition, task processing speed, auditory

\footnotetext{
${ }^{9}$ Retrieved from https://s3.wp.wsu.edu/uploads/sites/2101/2018/03/ECSR_Presentation_UW-PovertyCenter_March_2018.pdf?x99454.
} 
attention and interference control (the ability to filter out distractions), (DePrince, Weizierl, \& Combs, 2009). Van der Kolk (2014) similarly refers to executive functioning as the emotional brain's ability to inhibit, organize and modulate. It is difficult to imagine a classroom functioning smoothly without working executive functioning skills. According to Harvard's Center for the Developing Child (2018), executive functioning skills are not skills we are born with. Neuroplasticity offers insights on helping the learner strengthen their executive function.

Plasticity as defined by Weiss and Wagner (1998) is "the study of (central nervous system) organization as a function of experience” (p. 1). Van der Kolk (2015) analogizes aspects of babies’ neuroplasticity as being akin to a mental map made from the person's emotions and input. Neurons form associations based on the person's experiences. These associated neurons begin to respond together to stimuli and input. In the child with secure attachment, associated neurons may respond to (social interaction, as an example) with cooperation and discovery, or the child (without secure attachment, or trauma-affected) may feel fear and abandonment. Insights from neuroscience on executive functioning and neuroplasticity suggest approaches for educators to help support learners build executive function skills and resilience, and to help guide trauma and poverty impacted learners toward new functioning cognitive pathways. These include metacognitive skills.

\section{What is metacognition? Helping learners recognize patterns of thinking.}

Most briefly, metacognition is thinking about one's own thinking, learning about one's own learning. Before getting into further detail, imagine a two-sided tool box, and in this example, the box is for students. One side contains information and guides on how the students learn (academic learning) and the other side has guides to how the students can learn about their own mind and state of being. The guides in the toolbox walk a person through concepts that are likely already familiar, but the procedures of them, and the conscious application of them, is the difference. Even though 
metacognition is the source of a rather large body of pedagogical work, the word itself can be cumbersome and can feel overly technical. Tools of metacognition are discussed in fields of education pedagogy (in curriculum design and classroom practices), social work and psychology (self-regulation and reflection), and neuroscience and psychology of learning (brain functioning, and the brain's limbic system which is responsible for memory and survival). In this paper, there are two applications of metacognition that are described. One metacognitive application is help the learner identify patterns in how they learn and how they can improve their own learning process. This process illuminates the steps or processes of how information becomes learning or knowledge (based on current understandings of human learning from neuroscience). In education, metacognitive tools can be used to encourage learners to identify the parts of their thinking, where they learn to recognize their own thinking, process of cognition and learning. Horvath and Hattie 2017 note that one aspect of learning is that of memory building. With memory building, they emphasize that in addition to helping learners with skills of memory building, where they learn to link new information to prior knowledge, it is vital to encourage the learner to do so correctly. This approach is highly metacognitive. Metacognitive tools can be embedded within curriculum design to help foster student and classroom reflection and deepen student learning. The other application of metacognition described in this paper refers to what I call a metacognitive state, which is where the learner is conscious of their executive functioning. They can also be used to promote self-regulation and social and emotional health in the school setting, as is the case with mindfulness practices in general. Mindfulness practices have been linked to positive supports for a range of traumas, including benefits to the brain's own ability to regulate emotions and reduce mood swings (Supporting Brain Development, 2017). Many aspects of metacognitive tools for classroom use overlap with tools for emotional self-regulation. Metacognitive tools can help provide learners with a lifetime approach to how they think, which helps learners build agency and self-efficacy, making it 
applicable in social justice-informed education (personal empowerment and agency). Metacognition can also be used to support many roles that benefit the learner and support healthy, resilient school communities. Metacognitive tools can help poverty-informed schools by supporting their strong academic focus. I have been reminded that tools which seem applicable and helpful can be used to oppress others or to stifle their others' knowledge and voices. I wish to clarify that I see metacognitive tools here as tools to address academic thinking and help regulate social emotional learning: these approaches should never stifle people's own ways of knowing, learning, intuiting, perceiving, but should instead provide insight into the rules and the how-tos for this significant social construct.

Van der Kolk (2013) refers to mindfulness (where he draws similarities to a metacognitive state) as observing with neutrality and non-attachment one's thinking and feeling. He provides insights from a clinical setting where his Post Traumatic Stress Disorder (PTSD) patients benefited from seeing an Electroencephalogram (EEG) display the patterns of activity in their brains associated with areas of difficulty focusing and regulating emotions. Bremner 2006 cites that PTSD affects $\sim 8 \%$ of Americans at some point in their lives. Van der Kolk describes their shift from selfcriticism to recognition of their need to learn to new ways to process their experiences. Wilson and Conyers (2013) address one view of metacognition as learning as a process of bringing in new information and assigning a learning goal, to then analyzing and thinking critically about the information, and then expressing their learning. It may not yet be doable to administer EEG (neurofeedback sessions) to all learners so they can see their own thinking, but metacognitive strategies can help the learner practically begin the journey of learning how their own thinking works, and how to improve it. 


\section{Best practices: supporting protective factors and supporting mitigation of risk exposure}

Best-practices exist for trauma-informed classrooms and for trauma-impacted schools. At the root of these best-practices is the understanding from a public health viewpoint that an individual (in this case, learner) can experience exposure to risk factors or protective factors which shape the individual's life outcomes. Risk factors can expose an individual to risky behaviors or circumstances, which can negatively impact their health and life outcomes. In their 2018 study, Blodgett and Houghten, include a community-wise scale that looks at risk and protective factors, as well as school-wide factors. Risk factors include ACEs and poverty, as noted by Blodgett and Houghten. They also correlate that the social environment of our communities, families and schools provide both and the risk of exposure of ACEs, and sources of resilience. Youth.gov (2018) refers to risk and protective factors across the domains of personal; school, neighborhood and community; and family Protective (or support) factors in an individual's life include healthy loving support and access to opportunities for personal development, which help build resilience. Resilience-building approaches consider the entire school and community by combining commonalities found in resilience and informed best-practices. By applying a community-scale lens, the needs of all learners are addressed. Resilience broadly refers to one's individual resources to protect, balance or buffer the individual from deleterious outcomes of risk exposure. Fostering school- and community-wide resilience is a widespread commitment of schools and school systems. Conversations around resiliency are generally aimed at the entire school and community. Although resilience techniques may vary based on ages of youth and stages of development, commitments to resilience is not aimed for just a specific subpopulation. Resilience is generally understood to benefit everyone, as part of what humans need for social and emotional health and wellness. Commonalities between traumainformed classroom practices and characteristics from high-performing, high-poverty schools can be 
taken together which can help provide effective techniques for addressing the needs of all learners by strengthening school and community-wide resilience.

For this paper, I conducted two additional informal interviews not mentioned in my methods. I met with Dr. Mandy Davis, co-director of Trauma Informed Oregon and a PSU School of Social Work Researcher, and in describing her work with the State of Oregon, she emphasized the importance that trauma-informed practice be systems-focused. Trauma-informed education ${ }^{10}$ needs to include the entire learning environment (also referred to by some as the learning ecosystem), from pedagogy, curriculum, educational policies, staff, administrators, discourse, and the buildings and facilities - it needs to be holistic to the child/ learner. Dr. Davis added that in order to reach all people, all learners, multiple learning modalities are needed. ${ }^{11}$ Horvath and Hattie (2017) emphasize the importance of multi-modal representation (modes of experience) in our brains as we process perception into application of problem solving, where a learner moves through levels of abstraction in thought.

\section{A school or district's strong academic focus and transparent practices empower the learner}

When a school has strong academic learning focus, it clarifies for the community the school's emphasis on their role in supporting the child to learn (where learning stands out from the other obvious roles schools perform). This may sound like an obvious focus for a school, but in a field dedicated to shaping the lives of children, explicitness of focus plays a role. Ritchhart, Church, and Morrison (2011) assert that thinking has been often regarded in relation to the student identified as accelerated or gifted. In trauma-informed schools, transparency (of rules, policies, grading rubrics,

\footnotetext{
${ }^{10}$ Trauma-informed education often includes training for staff and faculty to recognize the signs of trauma, and that the school or district has a plan to help guide students to additional support resources. The classroom activities are designed to avoid triggering trauma, and to help support all learners in greater-regulation, and resilience building. Trauma-informed classrooms recognize trauma's scope, and that there are approaches for possible recovery. Adapted and retrieved from https://www.samhsa.gov/nctic/trauma-interventions.

${ }^{11}$ Dr. Mandy Davis, https://www.pdx.edu/profile/mandy-davis, https://traumainformedoregon.org/
} 
student behavior expectations, power structures, and paths to student success) and empowerment (of the student) are vital characteristics. Metacognitive practices are often referred to as helping to make learning visible, which is both supportive of transparency and empowering to the learner. Characteristics of resilience-informed schools include visible, clear expectations of students (transparency). Another way to look transparency in academic settings is like sharing the so-called play book with the students (and the staff, and other faculty). Deep systematic approaches to transparency help build trust by ensuring that as much as possible, everyone receives the same procedural information and instructions. Metacognitive tools can be used to support clear expectations and as a mentoring device, strengthening resilience-informed practices. Transparent use of metacognitive approaches, and transparent expectations with developmentally-appropriate explicit instruction for task-specific requirements, can help be a check on metacognitive views, to keep them from being used proscriptively. It is worth noting here that there is disagreement about developmentally-appropriate learning progressions (Bransford, J., and National Research Council, 2000), a topic I regret that this paper cannot go into more discussion. Wilson and Conyers 2013 describe that classroom practices where the teacher mutually engages in learning with the class, where there is essentially not simply one expert in the room, as benefitting from metacognition approaches which are further enhanced by a social context. In this example, I find that it is the transparency of the teacher's aim to learn with the students that supports metacognition's role in student learning equity. Hattie and Yates 2014 (education researcher Hattie and cognitive psychologist Yates) cite reference to a method called cognitive task analysis (CTA); this description gets at the heart of what I feel is the value of metacognition and transparency in the classroom regarding learning instruction. "Instead of attempting to uncover the hidden aspects of expert knowledge, the students were better able to analyse the key underlying elements that determine how knowledge is generated and written-up within this complex disciplinary context." (p 77). Explicit 
instruction needs to be carefully paired with intentionality, intentionally applying the method to a specific task goal (and not to take-aways from the learning), to ensure room for the learner's own approach to the material and processes, and at the same time to provide them with the insights and cues they need to form their path to academic success. (Trauma Sensitive Schools, 2018) calls for a classroom setting where all learners are seen to have significant contributions, and where the schools explicitly connect trauma-impacted students to the community.

\section{Efficacy: our own beliefs and expectations about what we can do can impact cognition and academic performance}

Dweck and Leggett (1988) identify belief in one's efficacy (or effectiveness) as a model of motivations, identifying how a person perceives their own ability to achieve a range of goal types (social, performance, learning, and avoidance). They suggest that how a person approaches a task, (or what is the individual's own goal; is it learning or performance?) forms patterns of how they respond to tasks, based on what they believe in the context of the goal. Social psychologist Albert Bandura, best known for social cognitive theory (1993) refers broadly to Dweck and Leggett (1988) work in reference to "conception of ability" (p. 120). Social psychologist Carol Dweck and Ellen Leggett (applied psychologist), whose work on social cognition and motivation (1988) notes "our research with children has demonstrated that those who avoid challenge and show impairment in the face of difficulty are initially equal in ability to those who seek challenge and show persistence" (p. 256). Where Dweck and Leggett identify a range of motivating goal-types, Bandura (1993) identifies a range of efficacy types: personal (self), students' cognition, thought control, perception, coping efficiency and anxiety, social, self-regulation, parental, teachers', and collective-school. Bandura asserts that beliefs regarding self-efficacy impact cognitive processes and "play a key role in 
setting the course of intellectual development" (p. 135). They also suggest that academic teaching (writing for example) can help a student build their efficacy in that domain.

Researcher John Hattie who is most known for cognition research and meta-analyses work on effectiveness of education approaches created a rank of education influences measured by effect size. The second most effective is student's own expectations of how they will do, as measured by their self-reported grades ( $2^{\text {nd }}$ out of a list of 252 influences, Hattie Ranking Influences, 2018). At the top of his 2018 ranking Hattie lists collective teacher efficacy (collective efficacy here refers to teachers' belief in their ability to positively affect students, again out of a list of 252).

\section{ANALYSIS/DISCUSSION}

Education practices are not static. They should reflect and help guide the "...evolving standards of decency that mark the progress of a maturing society" (in the case's context, Justice Thurgood Marshall, Trop v Dulles, 1958, was not speaking directly of education, but he was speaking of culturally and temporal shaping of society, and the Supreme Court's need to embody that.) Today's educational conversations generally include a base of understanding of the importance of social-emotional learning (SEL) ${ }^{12}$ in an educational context, which reflects updated viewpoints on how students' emotional needs and expressions may fit into an academic sphere. Many educators recognize that SEL is integral to education, not just important. "As young children develop, their early experiences literally become embedded in the architecture of their brains." National Scientific Council on the Developing Child (2004), (p.1). There are numerous approaches to education that are effective when applied well. Many of these approaches sound remarkably similar (one example is that metacognitive reflection sounds a lot like the roots of critical thinking, and SEL sounds a lot

\footnotetext{
12 SEL: refers to supporting, in a learning context, healthy adult-child relationships as foundational for the child's ability to grow necessary emotional skills to interact and plan their future
} 
like attachment theory and self-regulation). What SEL can do so well is help communities at large to recognize and hopefully coalesce around this essential concept. The words are understandable, without jargon. This paper is not about SEL per se, but I believe the following conversation could not take place without that base of understanding.

The case in all standards and best-practices is that each practice has numerous versions. What differentiates most programs or best-practices is often with where subtle emphasis is placed. This section discusses the value of placing emphasis on metacognition, transparency, and in-depth review of content taught and point of view of content with the aim to more fully and accurately represent human experience and history of knowledge.

\section{\#1: Metacognition: a user's guide to our brains, development and cognition: Metacognitive approaches support education justice}

By grounding conversations on the biological brain processes of thinking and learning, focus can be centered on the brain's ability to grow, and learners' abilities to learn. I find it quite revolutionary that biological and psychological language about the brain and its cognitive functions is available for expanding the academic vocabulary around learning. Brain, cognition, executive functioning, neural pathways, plasticity, and memory retrieval are examples words that help specify function and help illuminate brain processes. Considering cognition in terms of brain processes and functioning helps dispel prior beliefs which held an air of inscrutability: contrast that with what we

once had, which were minds, and they were a terrible thing to waste. This language helps us to connect with universality of experiences with our human brains and learning. It provides the potential for us to begin to look at brain functioning like we do the functioning of our hearts or lungs. A learner that has been made aware of basic functioning of the brain — and shown how learning works — to apply those steps to their thinking and information processing. 
Neuroscience may continue to update the factual details of cognition and we may come to learn that what we understand now is incorrect. With that consideration, some learners may find it helpful to look at the metacognitive tool box as study tips. These are the steps that underpin most of metacognition in learning: mindfulness (as a state), observation (of intake of new material), planning (create a plan to learn new material), reflecting (seek feedback and consider one's understanding of new material in context with existing knowledge), and revising (make any needed corrections). There may be little contest regarding these study tips.

A school or district may benefit most from metacognitive practices by having a comprehensive plan in which metacognition is explicitly stated and clearly outlined. In a comment on complexities of their research on noncognitive factors in education, Farrington, Roderick, Allensworth, Nagaoka, J., Keyes, Johnson, and Beechum (2012) highlight the importance of ensuring that concepts are clear and distinct for "each step of in complex interactive processes" (p. 74). They note that conflagration of terms in the research realm leads to less usable findings. They call for the research to be extremely careful separating not only concepts, but student actions, and ultimately, how each aspect can be evaluated for evidence of impact on student outcomes. I find that same concern regarding the need for more conceptual clarity also applies to schools and districts. Similarly, it is observed by Roderick, Allensworth, Nagaoka, J., Keyes, Johnson, and Beechum that the broader school environment and its initiatives have a role in overall student performance.

\section{Where do we learn how to learn?}

There is a curious lack of stand-alone course teaching on learning strategies across disciplines, notes Roderick, Allensworth, Nagaoka, J., Keyes, Johnson, and Beechum (2012). At the time of their report they found one such college course taught in Canada. What I encountered was a 
repeated thread that metacognition should not be taught as a stand-alone course, that the methods for metacognition in one domain do not necessarily translate to another. That argument to me only highlights the value of a stand-alone course. A stand-alone course can teach not only the fundamentals of metacognition, but it can also share domain-specific insights and tips. Veenman, Elshout, and Meijer (1997) assert that if the learner is adequately exposed to a number of domainspecific metacognitive approaches, they may learn to recognize how to do so for other domains. I noted broad reluctance in education to teach learning skills and metacognition as stand-alone courses; as an aspect of how metacognition is presented. I do also recognize that teaching metacognitive skills as embedded into a domain or course is also valuable: I argue that both approaches are important. Many aspects of metacognitive tools for classroom use overlap with tools for emotional self-regulation, which can be empowering and help students plan for their futures. Planning for the future may contribute to life outcomes which can help break the cycle of poverty and trauma. Tools for social justice education call for fostering student agency, which metacognitive tools can also support. It may benefit neuroscience of learning research to design studies which also capture data for populations of trauma and poverty impacted learners.

\section{\#2: Transparency, a lens for supporting education justice}

Transparency supports healthy interactions and allows for the necessary scrutiny for an equitable education. I consider metacognition and transparency as closely related, in that metacognition requires that the process not be obscured. But transparency also refers to many aspects of institutional practices, as well as attitudes and intentions. In trauma-informed bestpractices, institution-wide transparency is called for. Transparency in education has been gaining traction for many years, but I argue for a more thorough application. Transparency and trustworthiness are to be fostered among all colleagues, staff, administrators, school employees and 
students' caregivers. With the student relationships with teachers, administration, staff and counselors, compassionate and dependable relationships are emphasized, along with transparency of expectations. But in the trauma-informed classroom, transparency could take a particularly strong role. Transparency in the classroom means that teachers clearly communicate classroom rules and expectations of behavior, and also that they clearly communicate learning goals and outcomes, sharing grading rubrics and all grading evaluative components. Providing students with evaluative rubrics supports an equitable learning environment by providing more transparency and by helping students better understand the learning goals and classroom expectations. The sharing of rubrics (which is a fairly common practice, but still not uniformly used) also provides another tool for students' metacognition, by helping them better understand the components of a learning system. Students can also gain more insight on how to prioritize what they are learning if they have access to the instructor's hierarchy of their learning goals for academic success. This will also help student to recognize for themselves evidence of their learning. This applies to every lesson, every day, and also to the broadest expectations of student conduct. This attention to transparency is designed to help foster the trust of the trauma-impacted learner, and the entire class (adapted from SAMHSA News, 2014).

\section{\#3: Education for all learners: examining content and point of view for all instructional material}

Now we have more tools to teach all learners. Depiction of knowledge needs to represent the world around us. A strong tenet in education justice (education equity refers to both education equity and incorporates that a just education needs to be in context of the learner's community and also that the education be reflective of the learner's own goals) (Levitan, 2016), and in social justice education is a call to increase representation of what's being taught, by whom it's being taught, and 
across examples whenever humans are depicted or described. The field of critical theory encompasses this view as well. This paper cannot delve further into critical theory but as I understand it, is a critical stance and not an ideology. Social justice education and education justice informed practices call for learning about and directly addressing societal injustices and oppressions in the classroom, as a healing and empowering tool. One principle in trauma-informed education is that trauma and stress must be understood. I see these related as directives to help get sources of suffering out of the shadows of the learners' lives. Learning techniques need to explicitly address the trauma and poverty affected populations. There needs to be an open acknowledgement of trauma and its impacts. Good learning techniques and environments allow space for these factors so that the students can reflect for themselves. It is of course imperative that this teaching be extremely sensitive of possible specific connections to a learner in the classroom, and to teach as much as possible without retraumatizing or sharing trauma in the group. It is beyond the scope of this paper to describe more on this, but it is important that I note that the classroom is not expected to be the place for counseling or truth in reconciliation. This point especially regards the material being taught (is the history of this subject being represented as thoroughly as possible? Are there other examples that could be taught, possibly lesser known, from other cultures? When people are depicted or described, is there a true commitment to showing a range of people doing a range of things? Are a range of people depicted or described when experts or exemplars are presented?). It also regards how material is presented, including considerations of information styles from a variety of cultural styles, and a variety of media to present the learning.

Teacher and writer Lisa Delpit points out that providing students with broad perspective is the task of educating for a democratic society. She emphasizes that the quality of teaching is also vital (as interviewed in Ayers Hunt and Quinn, 1998). Using broad perspective when teaching lessons enriches the learning for everyone. The body of human knowledge comes from people 
everywhere, and it belongs to everyone. It is the inheritance of our species. It also helps students better understand the context of contemporary life, and it helps address some of the inequality that many students likely observe and experience.

Three tenets in trauma-informed education, empowerment, choice (or supporting agency and self-awareness), and understanding trauma and stress support this approach. To empower the learner includes that learners need to be able to recognize themselves in positive examples. To help support choice, agency and self-awareness learners benefit from being exposed to other viewpoints. To support understanding trauma and stress, learners benefit from understanding broader social and historical context of human stressors.

In social justice-informed education practices, transparency takes a strong role, which includes transparency of admission policies and practices, as one example. Khan (2012) includes a chapter "Serving the underserved" (p. 221). Khan states his commitment to teaching all learners. He also asserts his videos provide opportunities to help "toward leveling the playing field" worldwide (p. 222). So, it is apparent the world and education equity are on his mind. His videos and content would benefit from broadening their depiction and examples of human knowledge and by broadening their delivery tone and inflection.

I pick up this conversation again later in the content analysis of Khan Academy, which can be found in Addenda I. Although the content analysis explores the themes and arguments of this paper, and since the topics are closely aligned but not entirely reciprocal, the content analysis is not included in the body.

\section{CONCLUSION}

Neuroscience findings suggest that our infant and developing human brains are "hardwired" for solid connection with a caregiver (attachment). Attachment provides us with the foundations of our brain's requirement of meeting our most basic needs and allows for the baby brain to process 
non-threatening information and input with more sensory involvement and more neural-pathway movement to the hippocampus and the temporal lobe (Supporting Brain Development, 2017), locations of language processing and locations associated with higher order cognition. Without that connection, or when that connection is disrupted by trauma (events or circumstances, physical or health) and conditions of poverty, we begin to process information, including sensory information, according to the impacted course of our neural pathways: which is part of the fight or flight response. This response initiates and redirects the brain functioning to the amygdala portion of the brain and sends additional blood flow to the heart and lungs. The nervous system engages the cortisol hormone (and others) to assist in stamina and focus for a threat circumstance. Responses which redirect neural pathways and alter hormones toward fight or flight contributes to the process of interruption of higher cognition. These responses also impact human interaction, which is essential to human development. The learner affected by trauma and poverty may perceive threat from social interactions and settings where there is no threat, as in everyday classroom interactions, as one example (Van der Kolk, 2015).

In 2014 the State of Alaska reported public health costs associated per person's ACE exposure was an estimated $\$ 43,375$. They also reported a state-wide cost impact public health costs in adults with deleterious health outcomes associated with ACEs of $\$ 775,649,000$ (for scale, they cited their entire public health state budget at $\$ 2,927,649,000)$. These figures do not include the other associated deleterious possible life outcomes including incarceration, reduced educational attainment. The CDC cites the cost of $\$ 124$ billion dollars (population-wide, for lifetime costs); it includes factors of productivity loss, health care associated costs, special education, child welfare, and criminal justice (Veto Violence CDC, 2018). As mentioned, public school populations today have over $51 \%$ poverty affected. Trauma affects no less than $30 \%$ of any school population, though the number is challenging to pinpoint, in part because we may not know what children have been 
exposed to. These numbers suggest that educational practices which do not embody traumainformed and poverty-informed practices are aimed for only a portion of the classroom.

Metacognitive tools are derived from studies from cognitive neuroscience and learningpsychology: these tools provide a person with specific, actionable steps to help recognize and guide their own thinking and learning and memory-use. They also provide neutral language to help the learner consider thinking as biological process, one which is universal among humans. This aspect of universality may be empowering as it helps a learner focus on the process of building their learning, and away from impacts of stigma or shame. Educating all people means educating people who have been impacted by trauma and poverty.

Metacognitive practices are tools which can help a learner focus on creating and repeating neural pathways leading to higher order cognition and learning. Higher order cognition is associated with executive functioning processes (which help facilitate social interactions). In the classroom setting, there is a widely used learning tool called Bloom's Taxonomy of Learning Objectives (written in 1956, revised in 2001) ${ }^{13}$. The classroom tool is derived from Benjamin Bloom's research on a hierarchy of stages for processing thought, and relates ideas of how our brains process and retrieve memory, to our basic understanding of academic learning, and open pathways for metacognitive pathways (see Chart/ image 1: Revised Bloom’s Taxonomy). The Bloom’s taxonomies help pinpoint learning tasks of higher-order cognition, as well as the other cognitive stages. The tool cites these cognitive stages — knowledge, comprehension, application, analysis, synthesis and evaluation — in ascending order, with evaluation being the most sophisticated. (This tool has many versions, and notably, was revised to indicate the action of the learning stage, as in: remember, understand, apply, analyze, evaluate, create.) Robert Marzano created a system called the

\footnotetext{
${ }^{13}$ Bloom's Taxonomy reference example, derived from Bloom's research. Retrieved from https:/teaching.uncc.edu/services-programs/teaching-guides/course-design/blooms-educational-objectives
} 
Taxonomy of Educational Objectives in $2000^{14}$, which identifies retrieval, comprehension, analysis and knowledge utilization. These taxonomies, and especially the shift toward the actions of learning, provide a language for describing and planning dynamic classroom lessons, and form some of the underpinnings of active learning methods.

Active learning strategies (active learning is gaining wide acceptance) aim to engage students across the objectives or stages by 1) making the student aware of the processes of thought sophistication and 2) making sure that the learning environment is less passive for the student, and away from the model where students primary learning comes from receiving a lecture. In a slight difference of opinion on active learning, Hattie and Yeats (2014) comment that a learner's careful observation can lead to learning, and that active learning can come from student engagement, and that learning is not necessarily increased by explicit student activity. Interestingly, the online learning platform Coursera notes that their all-time most popular course with over 180 million users is Learning How to Learn, by Professor Barbara Oakley (to date, 2017). ${ }^{15}$ In a New York Times interview Prof. Oakley declares that student frustration over learning (say, math) may be because they don't understand how their minds process information. ${ }^{16}$ The popularity of this course suggests to me that there is broad interest in how people learn. Sometimes I found I have to go off the beaten path to find information. For this final note, I'll quote from Dr. Barbara Oakley's website page where she reviews and recommends other authors' books on a range of topics, mostly human learning, and aspects of success, etc. "There are so many books to help teachers understand how younger students learn. But you may be surprised to learn that there are virtually no books for those

\footnotetext{
${ }^{14}$ Marzano Taxonomy reference example, derived from Marzano's research. Retrieved from https:/ec.ncpublicschools.gov/instructional-resources/bright-idea/new-taxonomy.pdf

15 Retrieved from https://www.kqed.org/mindshift/49697/5-strategies-to-demystify-the-learning-process-forstruggling-students and https://blog.coursera.org/year-review-10-popular-courses-2017/

${ }^{16}$ Retrieved from https://www.nytimes.com/2017/08/04/education/edlife/learning-how-to-learn-barbara-oakley.html
} 
students themselves, or for their parents."17 I find that the tools of learning how to learn support education justice.

This paper focuses on techniques and viewpoints to support education justice, but a limitation of this paper is that it does not elaborate on students' physical health needs, which are also vital to mood and hormonal health, cognition and overall human wellness. The paper also does not elaborate on the crucial aspects of human development and health from the perspectives of home, community, parenting or caregiving, and peer influence. These are areas for future research.

As I mentioned in methods, I volunteered at a Pacific Northwest High School classroom. My duties were to assist students' writing as they learned English. Their assignments were interesting and designed to engage the students and to grow their skills in language; their teacher also ensured that they received a broad exposure to gaining computer and technological competencies. A glance at $21^{\text {st }}$ Century Skills (sometimes called $21^{\text {st }}$ Century competencies) as per the World Economic Forum 2016 report New Vision for Education includes Information and Communication Technologies (ICT) as part of the top four foundational literacies in education. In the high school class, students had access to tablets in the classroom, and I noted a few recurring details about the process involved in using them. It took a lot of class time for each student to pick up their tablet from a station, students accessed their documents at different rates (due to technical glitches, or user error), and the network was unavailable on a few of my visits. The class lost some time and cohesion in the log-in process, which is not problematic on its own. But this class period was after lunch, and students with varied habits and varied access to nutrition lost attention easily. There is an anecdote cautioning that even "free" computers and technology gifted to a school can be costly to maintain, operate, and track. This was that experience, but, the access to technology, and how the teacher shared it with students, tells a different story. She worked with them to help them in personal

\footnotetext{
${ }^{17}$ Retrieved from: https://barbaraoakley.com/book-recommendations/
} 
expression projects, to create blogs, to create games or videos, to create photo essays, and to exchange writings internationally with other students. The class rippled with excitement and incredulity when the blog exercise was assigned: and when they began putting their blogs together, the classroom hummed and the students were nearly all excited and proud. What it felt like as an observer is that it meant a great deal to the students that they could connect to others in the global digital format, that they had something to say and to share, that they may in fact have an audience, and that some people in different power contexts seemed to care what they had to say.

There is no last word on any of these topics or themes discussed in this paper. There are many potent, impassioned, and smart arguments regarding quality education, some more equityseeking than others. It became apparent during this research that today's classroom is undergoing major technology and internet-based, globally-connected changes. A current education trend urges that education focus on creating a workforce for emerging technologies and new economic market forces; this reflects some of globalization's influence on education. The test known as PISA (Programme for International Student Assessment) further connects students globally. Founded in 2000, the volunteer-participation test occurs every three years, and uses a random-selection of 15 year- old students from 72 countries. Students are tested for knowledge and reasoning skills (not rote memorization) across science, math, reading, financial literacy. The test includes collaborative problem solving; since the entire test is on a computer ${ }^{20}$, the test process itself measures technological fluency. The PISA test describes its aims as toward greater education equity, and it tracks these subpopulations of learners (girl boy gender, social background, immigrant studies). The test aims to support equity by the following ways: each country can see their effectiveness of their own education system; each country can compare their information with others'; and those nations with improved education equity can share understandings with other nations. Education economists

\footnotetext{
${ }^{20}$ Retrieved from https://nces.ed.gov/surveys/pisa/
} 
Erik Hanushek and Ludger Woessman (2015) refer to the PISA test as a measurement of universal basic skills. In the context of universal basic skills which are measured by, with and for technological proficiency, the question of whether a technology gap will widen an achievement gap takes on new significance.

This paper aims to direct attention to ways of seeing learning in education, and ways to consider learners' experiences. What can learners take with them as they proceed through formal education? I hope they have portable nimble transformative messages. That they learn the basics of how a person learns academically, and that they have individual steps they can take to shaping their own brain and functions, as part of transparent and just education which acknowledges the shared human connection of our learning, neuroplasticity and resilience.

Many factors will push and pull and mold education and today education and learning can move quickly with technological communication and global technological changes; it is vital that learning, and all learners be kept in the focus of education.

\# \#

"Education should train a child to use his brains, to make for himself a place in the world and maintain for himself a place in the world even when it seems that society would shove him into the scrap-heap." Hellen Keller, Going Back to School, 1934 


\section{Addenda I: Content analysis: digital blended learning, global education, Salman Khan: education justice, metacognition and transparency}

Blended learning, learning which has both an online (digital, often video lesson based) and classroom (physical) component, has gained global traction in both formal school system settings and community or individual use settings.

Khan Academy, founded in 2007, is a nonprofit provider of education video lessons which are tailored to US Common Core standards as well as official online test preparation for the S.A.T. exam. Khan Academy advocates that their videos be used in tandem with physical teaching settings (a blended learning setting). How Khan Academy describes their vision of blended learning shares aspects of informed classrooms, specifically where the learner receives close attention from teachers in mentoring capacity, and where the student learns to direct their own learning pace and direction of inquiry. Khan Lab School is a small private school started by Khan Academy. Taking the available information on Khan Lab School and Khan Academy teaching and learning philosophies together, their practices appear to have some alignment with resilience-building practices. In the 2016 SigChi conference ("Education Reimagined") keynote, Khan talks about Khan Academy's current scale. At the time Khan Academy was being used in "190 countries, with 1,400,000 registered educators, 37,000,000 registered students and 5,000,000,000 problems answered". These self-reported numbers are extremely large, to be sure.

\section{Khan Academy and the trauma and poverty-impacted learner}

For the trauma and poverty impacted learner, there are likely advantages to be gained from carefully designed blended learning approaches. A report for industry titled the New Vision for Education (2016) advocates for embedding SEL into foundational ed-tech products. I find this both 
intriguing and disturbing: that not only is there a strong profit motive to increase social emotional learning, but that the arbiters of the digital education, corporations, are parsing and imparting social and emotional learning. It does also make sense that if companies are producing digital learning products, then one view would be that these products should incorporate the best tools available to teach the whole person. There are likely disadvantages for these learners as well, many of which stem from the premise that a student has access to technology and learning environment to participate in personal digital learning and can partake in the format. Then there are the dots to be connected to the full picture of what online learning is meant to be: supplemental, informational, behavioral support. Online learning is not meant to be the whole picture. My view is that education and learning provide a foundation for a learner to decide their path to their lifetime of careers and financial self-support, among other things. This is not the same goal as educating students to prepare for jobs, which are transactions of their time for money and benefits. Education equity requires that programs designed for learners not be created from a base of inequality and oppression. In order to do this, education needs to be transparent, and I believe we need judicious metacognition so the learner can drive their path and their communities can organically thrive. Due to the rise of blended learning and Khan Academy's growth in particular, it is vital to keep a focus on trauma and poverty sensitive education practices as digital and technological education grows worldwide.

Little data is available on effectiveness of blended learning for the trauma and povertyimpacted learner, but there are many points made by Salman Khan about education equity worldwide. To date, I have not located any research that Khan Academy has made public from their own data analytics on how learners use their videos, and/or how subsets of the population use their videos. From direct comments Khan makes when talking about the future learner dashboard features and real-time response tools Khan Academy is working to release, it is recognizable that Khan Academy has an unsurpassed amount of data from their video-lesson type of learning. 
Mastery learning, the approach embraced by Khan, is the concept that the learner progress to the next material in a topic or course when the individual learner has gained mastery of the content. This contrasts with the progression of most classroom settings where material taught progresses as a group, based on a schedule planned in advance. Mastery learning has some interesting intersections with the application of metacognition. In a mastery learning setting, the learner is made aware of the mastery approach, so at the onset the learner is encouraged to think in terms of how they are progressing toward content mastery, and how they are aware of planning of their learning. Khan's concept of mastery learning includes a physical classroom, and teachers who also perform mentoring roles. There are some interesting overlays of metacognitive opportunities in aspects of the video lessons of Khan Academy.

Feedback is key to the metacognitive processes of reflecting on and revising of one's work. How People Learn authors describe the benefit that technology can bring to increase teachers' speed of feedback time of student work (Bransford, J., and National Research Council, 2000). Khan also talks of his video platform providing at least three roles of feedback when the learner is logged in using the videos with a dashboard of features. First, the teacher has access to the learner's dashboard; second, the dashboard has real-time feedback and directional support for the learner. Khan argues on a third role of feedback made possible by video lessons, namely that the dashboard can capture the information of when students go back and review a previously viewed lesson. Khan asserts that since the video is available to the learner to be watched repeatedly, paused and slowed, that reinforces students' metacognition where they observe and take action on their own learning needs. (Khan here is specifically referring to when students follow lesson viewing with working on application of the lesson, or problem solving with the material from the lesson), ACM (2016). Khan Lab School 's document "Academic and Character Outcomes” lists what their students embody, which is a combination of features from social emotion learning, developed 
executive functioning, metacognition, and resilience-building. Their terms "character strength, cognitive skills, creation (as in student development of creative expression), purpose, independence" reflect what I see as future-forward. The language is positive, focused fully on the positive, and on where the KLS will help them get to. The language is not mired in untangling what is undesirable in a learner's life. Interestingly, this document also bears close resemblance to A variety of general and targeted learning strategies foster social and emotional skills, (see Chart/ image 5).

Metacognition is not explicitly described as a tool on KLS's website, but examples of metacognitive approaches are apparent in Architecture of Learning (2018), including reference to students setting learning goals, students learning to receive and apply feedback, and students learning to teach one another (preparation for teaching another person is highly metacognitive). KLS focuses its learning around Project Based Learning (PBL) where the students apply content knowledge to problem solving, during approximately half of their school time. At Khan Lab School, PBL aims to connect student learning with awareness of global affairs, and to KLS' Graduate Profile goals (goals which incorporate all of KLS' learning philosophies, including character strengths, global citizenship, purpose, independence and more). Many education settings embrace PBL, but since few are likely to be located in the headquarters of a major tech organization, like the Khan Academy headquarters, I imagine the Lab School's PBL to be a rigorous and life-changing educational experience.

Khan Academy displays a mix of transparency and non-transparency. It's easy to watch Khan Academy video lessons and not understand that for some video lessons, using the website can provide access to practice problems, and more. Neither Khan Academy's website nor its You'Tube page features information about Khan's full learning philosophies or vision for how the videos can be used in educational settings. Khan's book provides a lot of insight into his belief in the value of his video lessons to help free up to teachers' time so that the teacher role has more impact. He envisions that teachers can help in more of a mentor capacity and to be available for more 
personalized student assistance, for example. I find it puzzling that this information is not made more transparent and readily available. Why isn't Khan Academy more explicit about their vision for an entire learning-system approach? Are they leaving it to the video viewer to wonder how watching these videos alone may unlock a world-class education? Khan 2012 describes his approach as mastery learning, but fully realized mastery learning includes a classroom environment. Bransford and National Research Council (2000) note that in order for digital technology use in education to effectively increase learning, it has to be integrated into a cohesive educational plan.

Khan is experiencing such apparently massive success that perhaps the real concern with lack of transparency is whether by not making this information more apparent, do some students lose interest? Or, is it likely that some students like the presentation as it is? Perhaps there is benefit in general to keeping as little information as possible about Khan Academy learning, in an effort to keep learners focused simply on the video and content tools offered. There has been very little publicly-available research on KA, particularly on its effectiveness and user population. As of the writing of this paper, on July 24, 2018 they updated their website and I have now read their 2017 annual report, two peer-reviewed and foundation-supported research reports, one teacher-supplied letter report, and three foundation-supported reports. This is a scant number compared to their scale of 60,000 million registered users and 190 country-use reported for 2017. Prior to their posting in 2018 of their 2017 annual report, the location where I was able to see their reported number of users, and number of countries where they have users, was in keynote or panel talks (vs. Wikipediareported). It may be the case that Khan Academy is working on making more information publicly available. Khan Academy video and website use is completely free to the learners; to date that now includes SAT prep, and study tools for fourteen high school Advance Placement (AP) classes, K-12 math and an array of sciences and humanities, and most recently lessons for children ages 2-5. Khan Academy partners with school systems domestically and globally. It appears those partnerships 
produce customized solutions, platforms, content and more. Those services, I imagine, are not free. It appears foundations may support the use of Khan Academy in schools, and perhaps school systems also help pay for customized platform development, but I was not able to uncover those details. Similarly, Khan Academy's embrace of continuous improvement makes many aspects of controlled study research complicated. Additionally, since Khan often does not share the same language of describing their programs as most current educational pedagogies, it can be difficult to track them.

Holding Khan Academy accountable to rigorous transparency is called for when considering their unparalleled growth and international presence. This kind of growth is unprecedented in foundational K-12 education, originating from the US and spreading internationally. That this kind of growth can happen is so quickly is also important to note. (Massive Open Online Course (MOOCs) are generally college-level, and it is not in the scope of this paper to review MOOC growth, although I will mention Coursera's How to Learn MOOC). Khan Academy is creating customized platforms for education systems domestically and globally, and there is very little transparency about these often multiple-school projects with government entities and philanthropic funds. The last point on transparency and Khan Academy is of great concern: I would like to see them be more forthright about what kind of learner and user data they have amassed, and how they plan to use it, and perhaps it is the case that this information is forthcoming.

Khan Lab School's website displays transparency in conveying the four documents of their Learning Design (Architecture of Learning, Art of Teaching, Approach to Learning, Academic and Character Outcomes) and in the Curriculum document. Expectations and philosophies are clearly stated, and their website has quite a bit of information on daily life at their school, the teachers, and administrators. Discipline or academic concern policies I did not locate, but perhaps that can be found in a student/ family handbook. Transparency on KLS's admission 
policies and practices are absent from the website, and I think that could provide valuable insights into how Khan as an entity makes its own choices for their KLS physical school, from their base of digital KA and their learning philosophy rooted in educating all learners. It appears the student body is curated, and that limits the real-life application of the school being a lab. As mentioned, this paper looks at Salman Khan's work as an example of digital platform learning, with global reach, that teaches to K-12 (and more) to Common Core Standards, examining both what is stated and demonstrated in terms of education equity and justice. Salman Khan (2012) asserts that his philosophy of Khan Academy video format is to "flip" the classroom, an idea that refers to students doing something with their learning in the class and learning the basic lesson outside of classroom time (an idea which has long pedagogical roots). Students can watch Khan Academy video lessons before class, arrive to their classroom. ACM Keynote (2016) says this aspect of technology in the classroom can help humanize the learning that takes place in the class, where the teacher has more time with students to mentor and provide individual attention. Khan Academy's growth since its 2007 YouTube video-posting beginning draws my attention as I consider trauma and poverty affected learners. Salman Khan communicates strong messages of global learning equity in his book and in his talks. He also conveys a warm human touch on learning and conveys joy of learning and curiosity in the videos in which he is the instructor. Khan refers to Khan Academy in terms of a flipped classroom model. The flipped classroom flips the class-time use away from lecture instruction and toward what may have been previously viewed as homework where the students apply the learning (Kerr, 2015). Khan Academy provides to learners online no-cost access to videos and some supplemental material; what learners get is a product. Khan Academy can be a link to blended learning, when there is a physical school or community which is working programmatically with the videos; this would be a learning system. Khan Lab School is admittedly their practice-run school, small, and new. The school's philosophies include mastery learning, a self-directed learning 
approach (encouraging students to plan their own learning and education), and project-based learning (which fosters students' use of highest levels of the learning taxonomies, encouraging them to address complex creative projects). Right now, this is learning for a few. Khan Academy works with school systems, foundations, government entities globally in custom creation of programs.

Looking ahead, it seems there are possible economic impacts from blended learning models, where education money and types of pressures on governments to provide education may shift. These shifts may impact educators, school systems and written material providers. New Vision for Education (2016) noted that since 2011, \$ 5 billion dollars had flowed to ed-tech companies preschool through high school. Notably, nearly all of that is private investment, growing at an annual average rate of 32\% per year since 2011 (New Vision for Education, 2016). While this figure includes a range of products which primarily include language and literacy, tutoring and online learning, common core and platform, it indicates Khan Academy's educational content is free, and Khan speaks of communities and volunteers donating time and locations to help learners have a physical location (in places without schools). Khan Academy's website has a page on "Impacts" which include self-reported percentages of great educational impact. I would like to see the percentages separated for learners who are using the videos themselves, and learners who use videos as part of their school program.

Kerr 2016 refers to the flipped classroom as possibly fostering self-regulation and lifelong learning. To support those aims, she recommends providing the learner with four structured evidence-based steps to do so. Though she does not refer to them as such, these steps are metacognitive (and also self-directed) and support transparency of learning outcomes. First, she suggests students record their out-of-class worktime. This supports accountability, but also it helps lay the foundation for how to plan one's own learning. The second recommendation is for an inclass brief instructor-and-student-engaged refresher of the material (this helps with students' 
identifying gaps in their own understanding of material). Third, student evaluates their learning and progress based on rubric. The fourth suggestion calls for an online brief concept test before coming to class. Kerr does not specifically mention the role of tests/ evaluations as learning experiences but it is most essential that all student activities support learning (Handelsman, Miller and Pfund, 2007). I would also like to add here that Kerr directly suggests that these steps be used to redirect this process from teacher-centered: I agree that sharing the tools of metacognitive and transparent approaches can address both a power differential in the classroom and the learning environment, and that the learners themselves practice (tools) that can apply in nearly all contexts of contemporary social global life. Since this paper addresses K-12 primarily, I see that it is especially important that these tools be conveyed through the role of the teacher mentor, that there is a connection made between teacher and student and that the student is seen as an individual and as a whole conscious being. This connection is developmentally vital for $\mathrm{K}-12$, during years where humans need to experience failure and recovery, in a setting of trust and support (Seligman et al, 1995) (and arguably this is also the case throughout human emotional maturation which is well into the $20 \mathrm{~s}$ ).

Khan (2012) describes that his stripped-down approach to video content helps reduce distractions and helps the learner to focus on the lesson. A Khan Academy lesson-video contains this general format: lessons are about $10+$ minutes in length; the instructor is never depicted; the instructor's voice and captions are apparent; the lessons feature slow delivery of language with select phrases repeated; the screen display usually involves a full screen blackboard on which brightly colored text, numerals, signs, symbols, charts, graphs, small drawings appear as the instructor speaks (no hands are depicted); there may be the use of photographs or sometimes cartoon-type images. For the trauma or poverty affected learner, Khan Academy's video style (and possibly other blended learning options) may provide an opportunity to engage with the learning content material with fewer social pressures. 
Khan (2012) refers to education as a practice of continuous improvement. In education, it is also called an iterative or recursive process, recalling roots of Dewey's view. Dewey was wary of applying the concept that what has worked in prior education settings will necessarily work again. (Bransford, J., and National Research Council, 2000) note that research on education, as an iterative process, befits education, "research and practice flow in both directions" (p. 253) where research and practitioners inform each other. They further recommend aligning teaching materials, policy, and public opinion with ongoing research. 


\section{References}

ACM Conference on Human Factors in Computing. (2016). Closing Keynote Salman Khan, Education Reimagined. SigChi. Retrieved from https://www.youtube.com/watch?v=dNwvhPsFrnU.

Adams, J. M. (2013). Schools promoting 'trauma-informed' teaching to reach troubled students. EdSource: Highlighting Strategies for Student Success.

Anderson, L.W., Krathwohl, D. R. (2001). A taxonomy of learning, teaching and assessing, Abridged Edition. Boston, MA: Allyn and Bacon (chart excerpt). Retrieved from https://www.apu.edu/live_data/files/333/blooms_taxonomy_action_verbs.pdf.

Ayers, W., Hunt, Jean Ann, \& Quinn, Therese. (1998). Teaching for social justice: A Democracy and education reader. New York: New Press: Teachers College Press: Distributed by W.W. Norton.

Bandura, A. (1993). Perceived Self-Efficacy in Cognitive Development and Functioning. Educational Psychologist, 28(2), 117-148.

Barr, D. (2018). When trauma hinders learning. Phi Delta Kappan, 99(6), 39-44.

Beeks, Kathi (2018). The Lifelong Consequences of Childhood Trauma. High Country News. Retrieved from https://www.hcn.org/articles/the-montana-gap-the-lifelong- mental-healthconsequences-of-childhood-trauma.

Bertelsen, Phil (2016). PBS, NOVA, School of the Future. Retrieved from http://www.pbs.org/wgbh/nova/education/school-future/home/.

Biesta, G. (2007). Why “What Works” Won’t Work: Evidence-Based Practice and the Democratic Deficit in Educational Research. Educational Theory, 57(1), 1-22.

Blodgett, C. (2016). Improve Wellbeing and Resilience. ACEs Connection. Retrieved from https://www.acesconnection.com/clip/dr-chris-blodgett-from-aces-to-action-howcommunities-can-improve-wellbeing-and-resilience-106-minutes-alaska-children-s-trust. 
Blodgett, C. \& Houghten, M. (2018). No School Alone: Community Characteristics, Academic Success, and Youth Wellbeing. Child and Family Research Unit, Washington State University Extension. Retrieved from https://extension.wsu.edu/cafru/research/.

Blodgett, C., \& Lanigan, J. D. (2018). The Association between Adverse Childhood Experience (ACE) and School Success in Elementary School Children. School Psychology Quarterly, 33(1), 137-146.

Bloom, B. (1973). Recent developments in mastery learning. Educational Psychologist, 10(2), 53-57.

Bransford, J., \& National Research Council. (2000). Committee on Developments in the Science of Learning. (2000). How people learn: Brain, mind, experience, and school (Expanded ed.). Washington, D.C.: National Academy Press.

Bremner, J. (2006). Traumatic stress: Effects on the brain. Dialogues in Clinical Neuroscience, 8(4), $445-461$.

Bücker, J., Kapczinski, F., Post, R., Ceresér, K.M., Szobot, C., Yatham, L.N., . . Anna, M.. (2012). Cognitive impairment in school-aged children with early trauma. Comprehensive Psychiatry, 53(6), 758-764.

Burke-Harris, Nadine. (2015). How Childhood Trauma Affects Health Across a Lifetime, TED. Retrieved from https://www.youtube.com/watch?v=95ovIJ3dsNk.

Casssidy, J., Jones, J., \& Shaver, P. (2013). Contributions of attachment theory and research: A framework for future research, translation, and policy. 25, 1415-1434.

Centers for Disease Control and Prevention. (2016). Adverse Childhood Experiences Presentation Graphics. Retrieved from https://www.cdc.gov/violenceprevention/acestudy/ACE_graphics.html. 
Centers for Disease Control and Prevention. (2016). About the CDC-Kaiser ACE Study. Retrieved from https://www.cdc.gov/violenceprevention/acestudy/about.html.

Centers for Disease Control and Prevention. (2018). Social determinant of health: know what affects health. Retrieved from https://www.cdc.gov/socialdeterminants/.

Chief Education Office, State of Oregon. (2018). About. Retrieved from http://education.oregon.gov.

Chief Education Office, State of Oregon. (2017). Practices to Improve the Achievement of Students in Poverty (Legislative Report on House Bill 4057, 2016). Retrieved from education.oregon.gov.

Critical theory. (2005). Stanford Encyclopedia of Philosophy, Stanford University. Retrieved from https://plato.stanford.edu/entries/critical-theory/\#1.

Delpit, Lisa D. (1988). The Silenced Dialogue: Power and Pedagogy in Educating Other People's Children. Harvard Educational Review, 58(3), 280-98.

DePrince, A.P., Weinzierl, K. M., \& Combs, M. D. (2009). Executive Function Performance and Trauma Exposure in a Community Sample of Children. Child Abuse \& Neglect: The International Journal, 33(6), 353-361.

Duckworth, A., Quinn, P., \& Seligman, M. (2009). Positive predictors of teacher effectiveness. The Journal of Positive Psychology, 4(6), 540-547.

Durlak, J.A., Weissberg, R.P., Dymnicki, A.B., Taylor, R.D., \& Schellinger, K.B. (2011). The Impact of Enhancing Students' Social and Emotional Learning: A Meta-Analysis of School-Based Universal Interventions. Child Development, 82(1), 405-432.

Dweck, C. S., \& Leggett, E. L. (1988). A Social-Cognitive Approach to Motivation and Personality. Psychological Review, 95(2), 256-73. 
The Every Child Succeeds Act and Common Core Standards. (2015). Senate.gov. Retrieved from https://www.help.senate.gov/imo/media/doc/ESSA\%20$\% 20$ Ends $\% 20$ federal $\% 20$ Common $\% 20$ Core $\% 20$ mandate.pdf.

Examples of Engaging Instruction to Increase Equity in Education. (2015). Chapparo, Erin A; Nese, Rhonda NT; McIntosh, Kent. Positive Behavioral Interventions and Supports. PBIS is funded from US Dept. of Ed.'s Office of Special Education Programs. Retrieved from: https://www.pbis.org/Common/Cms/files/pbisresources/Engaging\%20Instruction\%20to \%20Increase $\% 20$ Equity $\% 20$ in $\% 20$ Education.pdf.

Farrington, C. A., Roderick, M., Allensworth, E., Nagaoka, J., Keyes, T. S., Johnson, D. W., \& Beechum, N. O. (2012). Teaching Adolescents to Become Learners: The Role of Noncognitive Factors in Shaping School Performance--A Critical Literature Review. Chicago, IL: Consortium on Chicago School Research.

Field, S., Kuczera, M, \& Pont, B., \& Organisation for Economic Co-operation Development. (2007). No more failures: Ten steps to equity in education (Education and training policy). Paris: OECD.

Filmer, D., \& Pritchett, L. (1999). The Effect of Household Wealth on Educational Attainment: Evidence from 35 Countries. Population and Development Review, 25(1), 85-120.

Flavell, J.H. (1979). Metacognition and Cognitive Monitoring: A New Area of CognitiveDevelopmental Inquiry. American Psychologist, 34(10), 906-911.

Going Back to School, as published in the Home Magazine 1934. (2018). American Foundation for the Blind. (2018). Retrieved from: http://www.afb.org/info/about-us/helen-keller/booksessays-and-speeches/on-education/going-back-to-school-as-published-in-the-homemagazine-september-1934/12345. 
Gorski, P. (2009). Insisting on Digital Equity: Reframing the Dominant Discourse on Multicultural Education and Technology. Urban Education, 44(3), 348-364.

Gorski, Paul C. (2016). Making Better Multicultural and Social Justice Teacher Educators: A Qualitative Analysis of the Professional Learning and Support Needs of Multicultural Teacher Education Faculty. Multicultural Education Review, 8(3), 139-159.

Gorski, Paul C. (2012). Perceiving the Problem of Poverty and Schooling: Deconstructing the Class Stereotypes that Mis-Shape Education Practice and Policy. Equity \& Excellence in Education, 45(2), 302-319.

Gorski, P. (2016). Poverty and the ideological imperative: A call to unhook from deficit and grit ideology and to strive for structural ideology in teacher education. Journal of Education for Teaching, 42(4), 378-386.

Greiff, Wüstenberg, \& Avvisati. (2015). Computer-generated log-file analyses as a window into students' minds? A showcase study based on the PISA 2012 assessment of problem solving. Computers \& Education, 91(C), 92-105.

Hacker, D. J., Dunlosky, J., \& Graesser, A. C. (Eds.). (1998). Metacognition in educational theory and practice. Routledge.

Handelsman, J., Miller, Sarah, Pfund, Christine, \& Wisconsin Program for Scientific Teaching. (2007). Scientific teaching (Wisconsin Program for Scientific Teaching). Madison, WI. Englewood, CO: New York, NY: Wisconsin Program for Scientific Teaching; Roberts and W.H. Freeman \&. Co...

Hanushek, Eric. A, \& Woessman, Ludger, (2015). Universal Basic Skills, What Countries Stand to Gain. OECD Publishing. Paris, France. Retrieved from http://hanushek.stanford.edu/publications/universal-basic-skills-what-countries-stand-gain. 
Hattie, J., \& Yates, Gregory C. R. (2014). Visible learning and the science of how we learn. London; New York: Routledge, Taylor \& Francis Group.

Hattie ranking: 252 Influences and Effect Sizes Related to Student Achievement. (2018). Visible Learning. Retrieved from https://visible-learning.org/hattie-ranking-influences-effect-sizeslearning-achievement/.

Harvard Center on the Developing Child. (2018). Executive Function \& Self-Regulation. Retrieved from https://developingchild.harvard.edu/science/key-concepts/executive-function/.

Harvard Graduate School of Education. (2015). Public Policy and Resilience: how we can change our policies to help disadvantaged kids cope and thrive. Retrieved from https://www.gse.harvard.edu/news/uk/15/03/public-policy-and-resilience.

Hernandez, D.J. (2011). Double Jeopardy: How Third-Grade Reading Skills and Poverty Influence High School Graduation. Retrieved from http://www.aecf.org.

Hochschild JL. (2003). Social Class in Public Schools. Journal of Social Issues. 2003;59 (4) :821-840. Retrieved from https://scholar.harvard.edu/jlhochschild/publications/social-class-publicschools.

Horvath, J., Lodge, Jason M., \& Hattie, John. (2017). From the laboratory to the classroom: Translating science of learning for teachers. London; New York: Routledge, Taylor \& Francis Group.

Joyce, K., \& Cartwright, N. (2018). Meeting our standards for educational justice: Doing our best with the evidence. Theory and Research in Education, 16(1), 3-22.

Kaufer, Daniela. 2011. What can neuroscience research teach us about teaching? Berkeley Graduate Division. University of California, Berkeley.

Retrieved from http://gsi.berkeley.edu/programs-services/hsl-project/hsl-speakers/kaufer/

Kerr, B. (2015). The flipped classroom in engineering education: A survey of the research. Interactive Collaborative Learning (ICL), 2015 International Conference on, 815-818. 
Khan Academy. (2018). Retrieved from https://www.khanacademy.org.

Khan Lab School. (2018). Retrieved from https://khanlabschool.org.

Khan Lab School. (2018). Architecture of learning. Retrieved from https://khanlabschool.org/learning-design/architecture-learning.

Khan, S. (2012). The one world schoolhouse: Education reimagined. New York, NY: Twelve.

Lai, E. R. (2011). Motivation: A literature review. Pearson Research’s Report.

Levitan, Joseph. (2016). American Journal of Education Forum. Retrieved from http://www.ajeforum.com/the-difference-between-educational-equality-equity-and-justiceand-why-it-matters-by-joseph-levitan/.

Lingard, B., Sellar, S., \& Savage, G. C. (2014). Re-Articulating Social Justice as Equity in Schooling Policy: The Effects of Testing and Data Infrastructures. British Journal of Sociology of Education, 35(5), 710-730.

Metacognitive Processes S. R. S. D. TEAL Center Fact Sheet No. 4:

Self-Regulated Strategy Development. Retrieved from https://lincs.ed.gov/state-resources/federal initiatives/teal/guide/metacognitive.

Metzler, Merrick, Klevens, Ports, \& Ford. (2017). Adverse childhood experiences and life opportunities: Shifting the narrative. Children and Youth Services Review, 72, 141-149.

Miller, P. (2012). Community-Based Education and Social Capital in an Urban After-School Program. Education and Urban Society, 44 (1), 35-60.

Morsy, Leila, \& Rothstein, Richard. (2015). Five Social Disadvantages that Depress Student Performance: Why Schools Alone Can’t Close Achievement Gaps. Economic Policy Institute, Economic Policy Institute. 
Munshi, K., \& Rosenzweig, M. (2006). Traditional institutions meet the modern world: Caste, gender, and schooling choice in a globalizing economy. American Economic Review, 96(4), 1225-1252.

Murphy, R., Gallagher, L., Krumm, A. E., Mislevy, J., \& Hafter, A. (2014). Research on the use of Khan Academy in schools: Research brief.

National Center for Education Statistics (NCES). (2018). Institute of Education Sciences (IES). US Department of Education.

Retrieved from https://nces.ed.gov/fastfacts/display.asp?id=27.

National Scientific Council on the Developing Child (2004). Children's Emotional Development Is Built into the Architecture of Their Brains: Working Paper No. 2. Retrieved from www.developingchild.harvard.edu.

National Scientific Council on the Developing Child. (2011). "Building the Brain’s Air Traffic Control System: How Early Experiences Shape the Development of Executive Function. Working Paper 11”. National Scientific Council on the Developing Child. Retrieved from https://developingchild.harvard.edu/resources/building-the-brains-air-traffic-controlsystem-how-early-experiences-shape-the-development-of-executive-function/.

New vision for education: Fostering social and emotional learning through technology. (2016). World Economic Forum. Geneva, Switzerland. Retrieved form http://www3.weforum.org/docs/WEF_New_Vision_for_Education.pdf

Neuroscience and How Students Learn, (adapted from Prof. Daniela Kaufer, 2011). Berkeley Graduate Division. University of California, Berkeley. Retrieved from http://gsi.berkeley.edu/gsi-guide-contents/learning-theory-research/neuroscience/\#further. 
Non-Regulatory Guidance (ESSA Guidance): Using Evidence to Strengthen Education Investments (2016). U.S. Department of Education. Retrieved from https://ed.gov/policy/elsec/leg/essa/guidanceuseseinvestment.pdf.

Percent of low-income students in U.S. Public Schools. (2013). (Data source U.S. Dept. of Education, National Center for Education Statistics, Common Core of Data). Southern Education. Retrieved from http://www.southerneducation.org/Publications/New-DiverseMajority/Percent-of-Low-Income-Students-in-PS-2015-01.aspx.

Purcell, K., Heaps, A., Buchanan, J., \& Friedrich, L. (2013). Pew Research Center. Retrieved from http://www.pewinternet.org/2013/02/28/how-teachers-are-using-technology-at-homeand-in-their-classrooms/.

Rhem, J. (2013). Using reflection and metacognition to improve student learning: Across the disciplines, across the academy. Stylus Publishing, LLC..

Rich, P. (2017). "Left Unsaid”: A Review of School of the Future. Comparative Education Review, 61(3), 662-665. Retrieved from https://www.journals.uchicago.edu/doi/10.1086/692650.

Ritchhart, R., Church, M., \& Morrison, K. (2011). Making thinking visible: How to promote engagement, understanding, and independence for all learners. San Francisco, CA: John Wiley \& Sons.

Rooks, N. (2017). Cutting school: Privatization, segregation, and the end of public education. New York: The New Press.

Roskams, J. (2014). The Developing Brain: Implications for Youth Programs (Kristen Anderson Moore Lecture, Webcast). Retrieved from Allen Institute for Brain Science. Retrieved from www.childtrends.org. 
Implementation of the SB 287 Funding Formula: Impact on Missouri School Districts. (2011). Senate.mo.gov. Prepared for the Joint Committee on Education by Stacey Preis, Ph.D. Retrieved from https://www.senate.mo.gov/jced/FundingFormula.pdf.

Rutter, M. (1987). Psychosocial resilience and protective mechanisms. American Journal of Orthopsychiatry, 57, 316.

Salman Khan Discusses One World Schoolhouse (2016). The Aspen Institute. Retrieved from https://www.aspeninstitute.org/videos/sal-khan-discusses-one-world-schoolhouseeducation-reimagined-aspen-institute/.

Seligman, M., Reivich, Karen, Jaycox, Lisa, \& Gillham, Jane. (1995). The optimistic child. Boston, MA: Houghton Mifflin.

Schraw, G., Crippen, K. J., \& Hartley, K. (2006). Promoting self-regulation in science education: Metacognition as part of a broader perspective on learning. Research in science education, 36(1-2), 111-139.

Schraw, \& Dennison. (1994). Assessing Metacognitive Awareness. Contemporary Educational Psychology, 19(4), 460-475.

Shonkoff, J., Boyce, W., \& Mcewen, B. (2009). Neuroscience, Molecular Biology, and the Childhood Roots of Health Disparities: Building a New Framework for Health Promotion and Disease Prevention. JAMA, 301(21), 2252-2259.

Skoll World Forum, Disruption. (2013). Blended Learning: The Proof and the Promise, Salman Khan, Sandy Speicher, Stacey Brewer, and Debra Dunn. Retrieved from http://skoll.org/2013-skoll-world-forum-disruption/.

Soffel, Jenny (2016). What are the $21^{\text {st }}$ Century Skills Every Student Needs? World Economic Forum. Retrieved from https://www.weforum.org/agenda/2016/03/21st-century-skillsfuture-jobs-students/. 
Southern Poverty Law Center (2013). Percentage of Low-Income in US Public Schools 2013 (data from US Department of Education, NCES, Common Core of Data.

Supporting Brain Development in Traumatized Children and Youth (2017). US Department of Health and Human Services. Child Welfare Information Gateway. Retrieved from https://www.childwelfare.gov/pubs/braindevtrauma/.

Suarez-Orozco, M. (Ed.). (2007). Learning in the global era: International perspectives on globalization and education. University of California Press.

Supreme Court of the United States. (2018). Trop v Dulles, 1958. Retrieved from https://www.supremecourt.gov/search.aspx?Search=trop $+\mathrm{v}+$ dulles\&type=Site.

Teaching Children From Poverty and Trauma. (2016). National Education Association. Retrieved from https://www.nea.org/assets/docs/20200_Poverty\%20Handbook_flat.pdf.

Tough, P. (2016). Helping children succeed: What works and why. Retrieved from (courtesy of Random House) http://www.paultough.com/helping/pdf/Helping-Children-Succeed-PaulTough.pdf?pdf=hcs-pdf-landing.

Trauma Sensitive Schools Explicitly Connect Students to the School Community (2016). Trauma Learning and Policy Initiative. Retrieved from https://traumasensitiveschools.org/traumasensitive-schools-explicitly-connect-students-to-the-school-community/.

U.S. Department of Education. (2018). About ed, overview. Retrieved from https://www2.ed.gov/about/overview/mission/mission.html.

Van der Kolk, B. (2015). The Body Keeps the Score. Brain, Mind, and Body in the Healing of Trauma. New York, New York: Penguin Books.

Veto Violence. (2018). Adverse Childhood Experiences. CDC. Retrieved from https://vetoviolence.cdc.gov/apps/phl/resource_center_infographic.html. 
Weiss, M., \& Wagner, S. (1998). What explains the negative consequences of adverse childhood experiences on adult health? Insights from cognitive and neuroscience research. American Journal of Preventive Medicine, 14(4), 356-360.

What is PISA? (2018). OECD. Retrieved at http://www.oecd.org/pisa/aboutpisa/.

What is Project-Based Learning? (2018). Khan Lab School. Retrieved from https://khanlabschool.org/learning-design/approach-learning/project-based-learning.

Wilson, D. L., \& Conyers, M. (2013). Five big ideas for effective teaching: Connecting mind, brain, and education research to classroom practice. New York, NY: Teachers College Press.

YouTube. Khan Academy. (2018). Retrieved from

https://www.youtube.com/user/khanacademy?reload=9.

Youth.gov. (2018). Risk and Protective Factors. U.S. Government. Retrieved from https://youth.gov/youth-topics/youth-mental-health/risk-and-protective-factors-youth. 
Addenda II charts and images 


\section{Chart/ image 1: Revised Bloom's Taxonomy.}

Retrieved from https://www.apu.edu/live_data/files/333/blooms_taxonomy_action_verbs.pdf

\section{REVISED Bloom's Taxonomy Action Verbs}

\begin{tabular}{|c|c|c|c|c|c|c|}
\hline Definitions & I. Remembering & II. Understanding & III. Applying & IV. Analyzing & V. Evaluating & VI. Creating \\
\hline $\begin{array}{l}\text { Bloom's } \\
\text { Definition }\end{array}$ & $\begin{array}{l}\text { Exhibit memory } \\
\text { of previously } \\
\text { learned material } \\
\text { by recalling facts, } \\
\text { terms, basic } \\
\text { concepts, and } \\
\text { answers. }\end{array}$ & $\begin{array}{l}\text { Demonstrate } \\
\text { understanding of } \\
\text { facts and ideas by } \\
\text { organizing, } \\
\text { comparing, } \\
\text { translating, } \\
\text { interpreting, giving } \\
\text { descriptions, and } \\
\text { stating main ideas. }\end{array}$ & $\begin{array}{l}\text { Solve problems to } \\
\text { new situations by } \\
\text { applying acquired } \\
\text { knowledge, facts, } \\
\text { techniques and } \\
\text { rules in a different } \\
\text { way. }\end{array}$ & $\begin{array}{l}\text { Examine and break } \\
\text { information into } \\
\text { parts by identifying } \\
\text { motives or causes. } \\
\text { Make inferences } \\
\text { and find evidence } \\
\text { to support } \\
\text { generalizations. }\end{array}$ & $\begin{array}{l}\text { Present and } \\
\text { defend opinions } \\
\text { by making } \\
\text { judgments about } \\
\text { information, } \\
\text { validity of ideas, } \\
\text { or quality of work } \\
\text { based on a set of } \\
\text { criteria. }\end{array}$ & $\begin{array}{l}\text { Compile } \\
\text { information } \\
\text { together in a } \\
\text { different way by } \\
\text { combining } \\
\text { elements in a } \\
\text { new pattern or } \\
\text { proposing } \\
\text { alternative } \\
\text { solutions. }\end{array}$ \\
\hline Verbs & $\begin{array}{ll}\text { - } & \text { Choose } \\
\text { - } & \text { Define } \\
\text { - } & \text { How } \\
\text { - } & \text { Label } \\
\text { - } & \text { List } \\
\text { - } & \text { Match } \\
\text { - } & \text { Name } \\
\text { - Omit } \\
\text { - Recall } \\
\text { - Relate } \\
\text { - Select } \\
\text { - Show } \\
\text { - Spell } \\
\text { - Tell } \\
\text { - What } \\
\text { - When } \\
\text { - Where } \\
\text { - Which } \\
\text { - Who } \\
\text { - Why }\end{array}$ & $\begin{array}{l}\text { - } \text { Classify } \\
\text { - } \text { Compare } \\
\text { - } \text { Contrast } \\
\text { - } \text { Demonstrate } \\
\text { - } \text { Explain } \\
\text { - } \text { Extend } \\
\text { - Illustrate } \\
\text { - Infer } \\
\text { - Interpret } \\
\text { - } \text { Outline } \\
\text { - Relate } \\
\text { - } \text { Rephrase } \\
\text { - Show } \\
\text { - Summarize } \\
\text { - } \text { Translate }\end{array}$ & $\begin{array}{ll}\text { - } & \text { Apply } \\
\text { - } & \text { Build } \\
\text { - } & \text { Choose } \\
\text { - } & \text { Construct } \\
\text { - } & \text { Develop } \\
\text { - } & \text { Experiment with } \\
\text { - } & \text { Identify } \\
\text { - Interview } \\
\text { - } \\
\text { - } \text { Make use of } \\
\text { - } & \text { Organize } \\
\text { - } & \text { Plan } \\
\text { - } & \text { Select } \\
\text { - } & \text { Solve } \\
\text { - Utilize }\end{array}$ & $\begin{array}{l}\text { - } \text { Analyze } \\
\text { - } \text { Assume } \\
\text { - } \text { Categorize } \\
\text { - Classify } \\
\text { - Compare } \\
\text { - Conclusion } \\
\text { - } \text { Discover } \\
\text { - } \text { Dissect } \\
\text { - } \text { Distinguish } \\
\text { - } \text { Divide } \\
\text { - Examine } \\
\text { - Function } \\
\text { - Inference } \\
\text { - Inspect } \\
\text { - List } \\
\text { - } \text { Motive } \\
\text { - Relationships } \\
\text { - Simplify } \\
\text { - Survey } \\
\text { - } \text { Take part in } \\
\text { - Test for } \\
\text { - Theme }\end{array}$ & 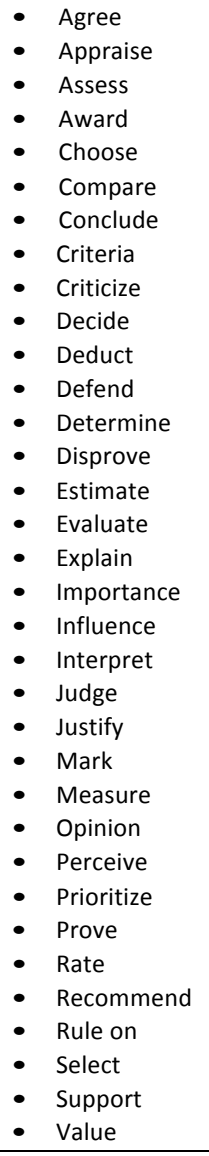 & 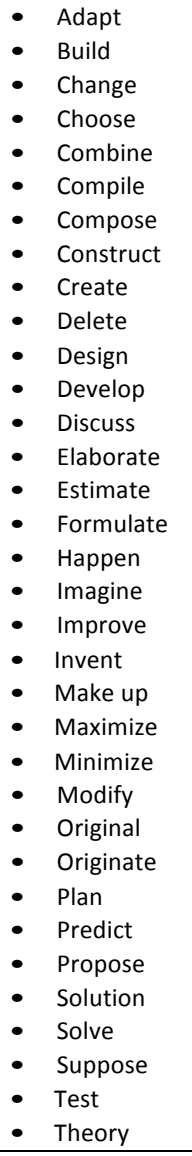 \\
\hline
\end{tabular}

Anderson, L. W., \& Krathwohl, D. R. (2001). A taxonomy for learning, teaching, and assessing, Abridged Edition. Boston, MA: Allyn and Bacon. 


\section{Chart/ image 2: How Common are ACEs? Infographic}

Veto Violence. (2018). Adverse Childhood Experiences. Centers for Disease Control and Prevention. Retrieved from

https://vetoviolence.cdc.gov/apps/phl/resource_center_infographic.html

\section{i HOW COMMON ARE ACES?}

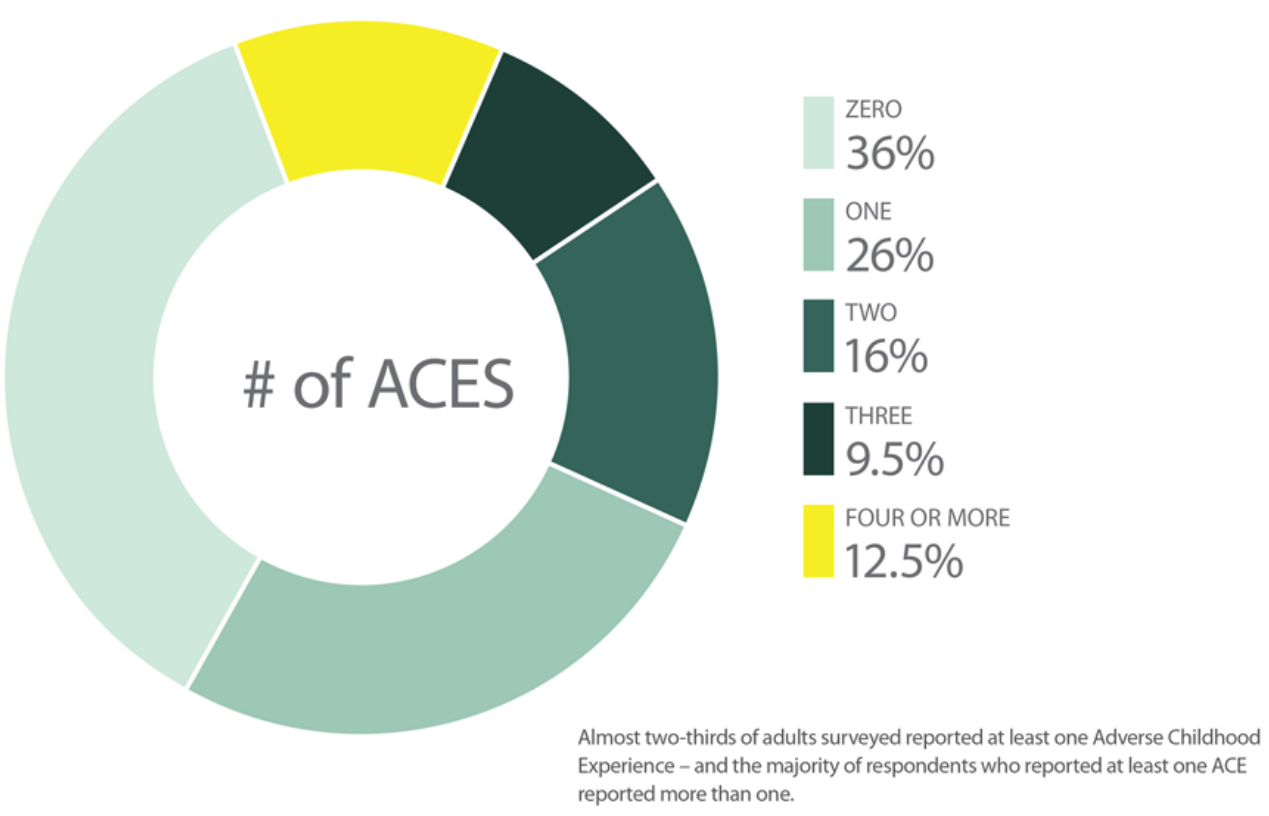

\section{TYPES of ACES}

The ACE study looked at three categories of adverse experience: childhood abuse, which included emotional, physical, and sexual abuse; neglect, including both physical and emotional neglect; and household challenges, which included growing up in a household were there was substance abuse, mental illness, violent treatment of a mother or stepmother, parental separation/divorce or had a member of the household go to prison. Respondents were given an ACE score between 0 and 10 based on how many of these 10 types of adverse experience to which they reported being exposed.

ABUSE

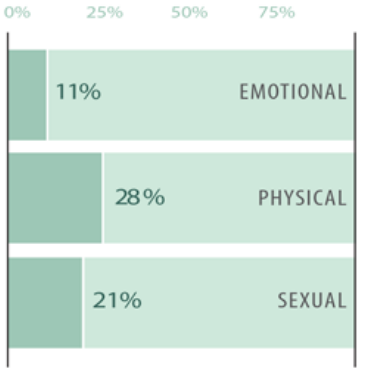

HOUSEHOLD CHALLENGES

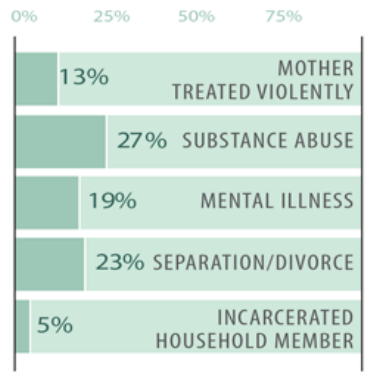

NEGLECT

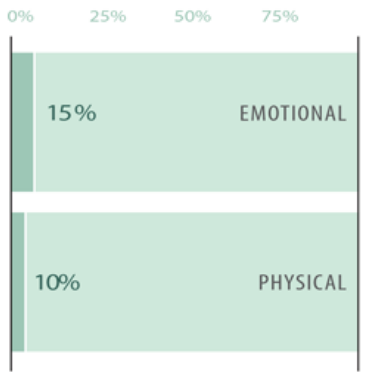




\section{Chart/ image 3: The ACE Pyramid Infographic}

Centers for Disease Control and Prevention. (2016). Adverse Childhood Experiences Presentation Graphics. Retrieved from https://www.cdc.gov/violenceprevention/acestudy/ACE_graphics.html.

The ACE Pyramid
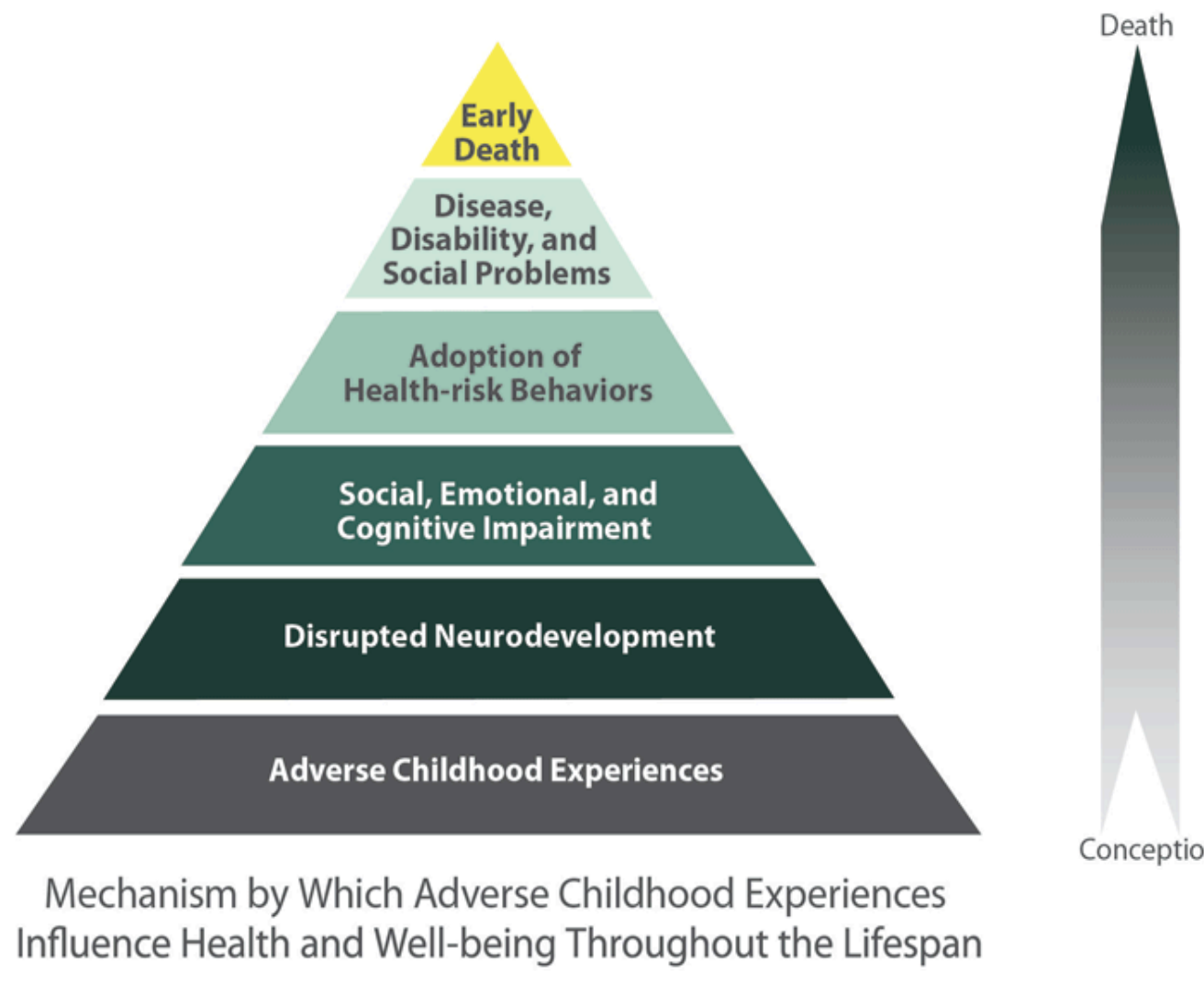

Conception Influence Health and Well-being Throughout the Lifespan 
Chart/ image 4: Students require 16 skills for the 21st century. World Economic Forum. (2016). Retrieved from https://www.weforum.org/agenda/2016/05/5-charts-that-explain-thefuture-of-education.

Exhibit 1: Students require 16 skills for the 21 st century

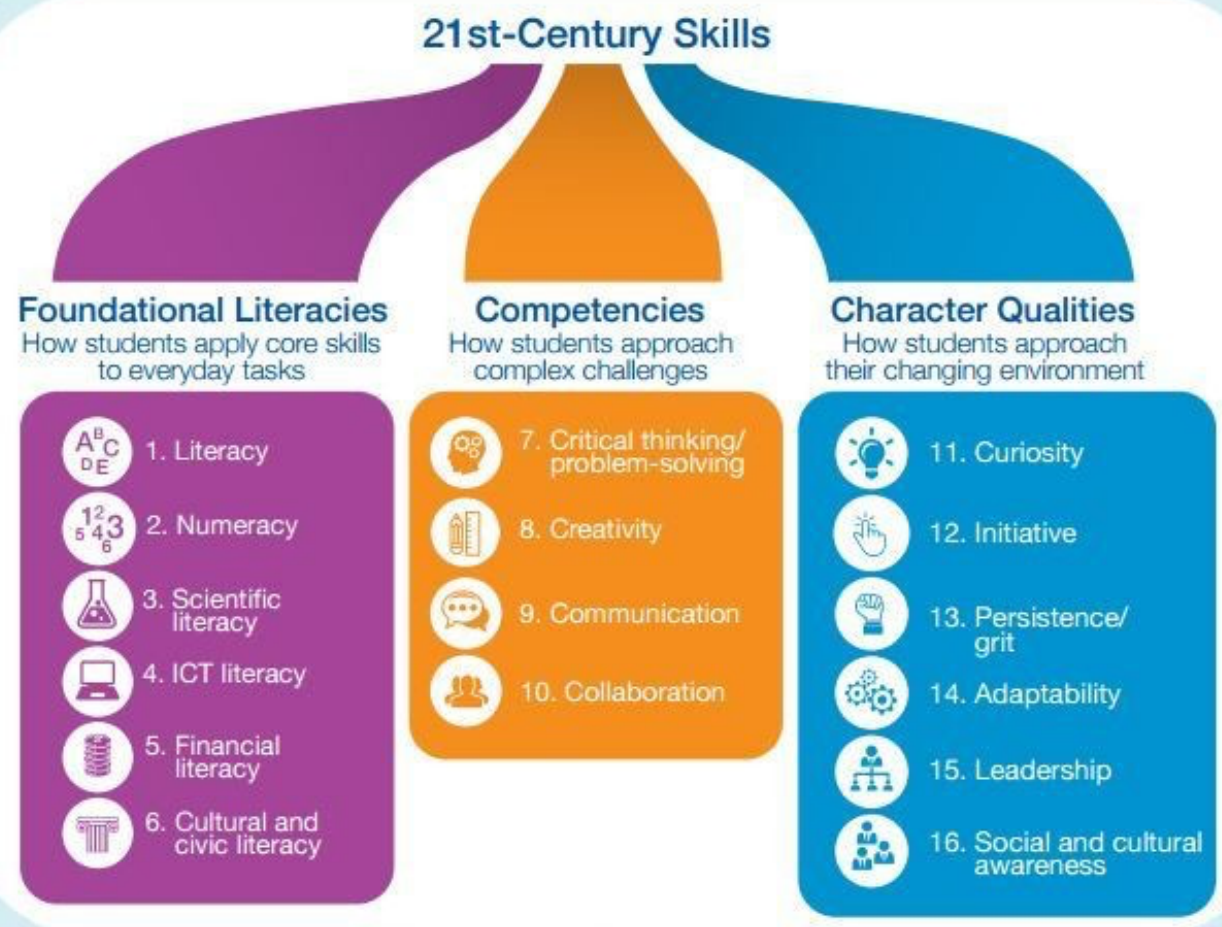

Lifelong Learning 


\section{Chart/ image 5: A variety of general and targeted learning strategies foster social and}

\section{emotional skills.}

World Economic Forum. (2016). Retrieved from https://www.weforum.org/agenda/2016/05/5charts-that-explain-the-future-of-education.

Exhibit 3: A variety of general and targeted learning strategies foster social and emotional skills

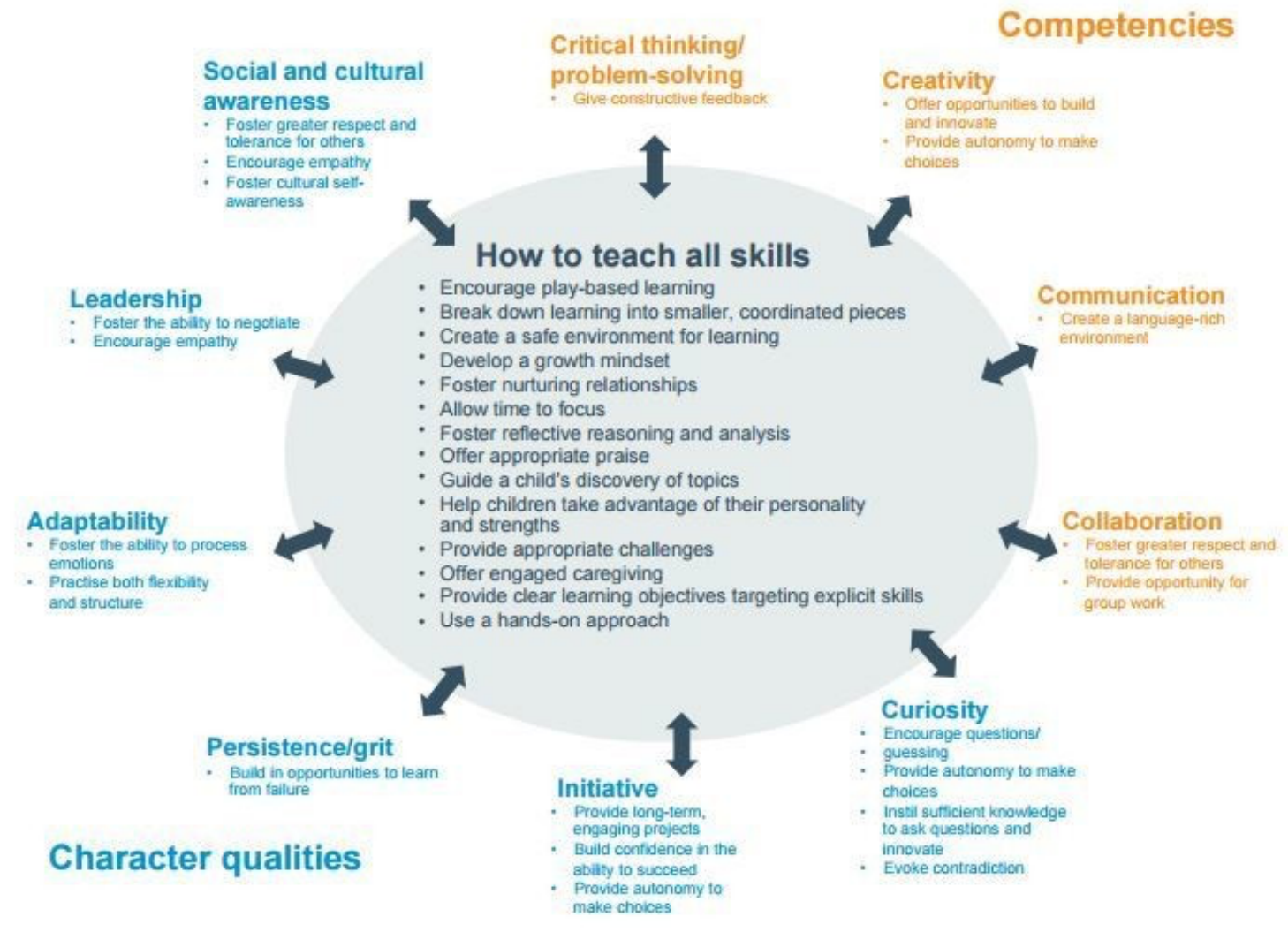




\section{Keywords}

Achievement gap, technology gap

$21^{\text {st }}$ century competencies

Social justice education, education equity

Nested inequalities, Socioeconomic status, SES, Critical theory

ACEs, resilience, efficacy, neuroplasticity

Metacognition, project-based learning, PBL

Bloom's Taxonomy, active learning, blended learning, mastery learning

Self-regulation, higher order cognition, executive functions

Khan Academy, flipped classroom, blended learning

PISA, education justice, social emotional learning, SEL

Structural inequalities 